\title{
Neuroprotective Effects of Hesperidin and Benfotiamine against Paraquat Induced Spinal Cord Neurotoxicity in Adult Male Albino Rats
}

\author{
Dalia M. Amin ${ }^{(0)}$, Shimaa H. Ameen, Marwa T. Abaza \\ Forensic Medicine and Clinical Toxicology Department, Faculty of Medicine, Zagazig University, Zagazig, Egypt \\ Email: daliaamin013@gmail.com
}

How to cite this paper: Amin, D.M., Ameen, S.H. and Abaza, M.T. (2021) Neuroprotective Effects of Hesperidin and Benfotiamine against Paraquat Induced Spinal Cord Neurotoxicity in Adult Male Albino Rats. Occupational Diseases and Environmental Medicine, 9, 139-164.

https://doi.org/10.4236/odem.2021.93011

Received: July 25, 2021

Accepted: August 27, 2021

Published: August 30, 2021

Copyright $\odot 2021$ by author(s) and Scientific Research Publishing Inc. This work is licensed under the Creative Commons Attribution International License (CC BY 4.0).

http://creativecommons.org/licenses/by/4.0/

(c) $\underset{\mathrm{By}}{\mathrm{i}}$ Open Access

\begin{abstract}
Introduction: There are extensive people exposures to paraquat (PQ) herbicide resulting in human health hazards. Aim of the Work: To compare the beneficial neuroprotective effects of hesperidin and benfotiamine on paraquat (PQ)-induced spinal cord neurotoxic effects in rats. Materials and Methods: Rats were divided into 4 groups as following: control, paraquat (PQ $20.8 \mathrm{mg} / \mathrm{kg}$, oral gavage (e.g.)), paraquat + benfotiamine $(50 \mathrm{mg} / \mathrm{kg}$, oral gavage (e.g.)) and paraquat + hesperidin $(40 \mathrm{mg} / \mathrm{kg}$, oral gavage (e.g.)). PQ is given as the previous dose. Rats are treated 6 days per week. Results: There was a significant increased mean value of malondialdehyde associated with a significant reduction in the content of reduced glutathione and antioxidant enzymes activities associated with a significant increase in Serum phosphorylated neurofilament $\mathrm{H}$, neurospecific enolase and s100 levels were recorded and significant spinal cord histopathological changes in paraquat treated group as compared to their corresponding values in the control group and immunohistochemical examination confirmed these results. Upon supplementation with benfotiamine and hesperidin to paraquat treated rats, there was a significant decrease in the mean values of malondialdehyde associated with a marked increase in the content of reduced glutathione and antioxidant enzymes activities associated with a significant decrease in Serum phosphorylated neurofilament- $\mathrm{H}$, neurospecific enolase and s100 levels were also recorded with significant improvement of spinal cord architecture when compared with the paraquat treated group. Conclusion: The use of benfotiamine and hesperidin produced a significant protection against all of the above-mentioned changes.
\end{abstract}

\section{Keywords}

Benfotiamine, Hesperidin, Paraquat, Spinal Cord, Toxicity 


\section{Introduction}

Paraquat (PQ) has a wide range of use as an herbicide, and one of the most important agents to control weeds in a variety of crops. PQ is not only hazardous to human health but also highly toxic to plants, farm animals and man [1] [2].

Oral, inhalation and damaged skin are the main routes of exposure to the paraquat. Paraquat Mortality rate is high because of suicidal attempts by its ingestion or occupational dermal damage. Paraquat is a corrosive agent to the skin make it is easily absorbed into the body. Due to its local accumulation, the lung is the primary site of its toxic effects [3]. Additionally, chronic exposure to PQ was recorded to be accompanied with liver failure, kidney failure, and Parkinsonian lesions with lung fibrosis [4].

Paraquat is environmental pro-oxidant pollutants that induce free radical release. At high concentrations, they cause oxidative stress, a damageable process that can impair cell function, structures and has been claimed in many pathological situations [5].

Thiamine (Vitamin B1) is essential for the nervous system. It is the precursor of thiamine Diphosphate (ThDP), an important coenzyme for transketolase, pyruvate dehydrogenase and 2-oxoglutarate dehydrogenase [6]. It is thus essential for nervous system energy metabolism. ThDP is formed by pyro phosphorylation of thiamine, a reaction catalyzed by Thiamine Pyro Phosphokinase (TPK) [7].

Presently, the most widely used is Benfotiamine (BNF). Initially, BNF was used to increase blood thiamine levels in patients suffering from thiamine deficiency. It was later shown to prevent experimental diabetic retinopathy [8]. More recently, BFT was shown to have powerful beneficial effects in mouse models of neurodegenerative diseases [9] [10].

Benfotiamine (BNF), an acyl thiamine derivative, is a powerful NADPH oxidase inhibitor that protects tissue injury in many experimental models [11]. Benfotiamine has been recorded to offer protection against diabetes mellitus complications as neuropathy, nephropathy and retinopathy [12]. Benfotiamine inhibits the Protein Kinase C (PKC) pathway, thus inhibiting the NF- $\mathrm{kB}$ activation in diabetes mellitus patients [13]. Moreover, benfotiamine activates the transketolase enzyme that eventually blocks the production of NADPH oxidase and increases the antioxidant properties (Figure 1) [14].

Flavonoids are compounds polyphenolic in nature that are obtained from all foods of plant origin. They protect biological organs against free radical-induced oxidative damage (Figure 2) [15].

Hesperidin (HSP) is a flavanone glycoside hugely found in orange and lemon and is a cheap by product of citrus cultivation [16]. HSP is beneficially supplemented in the complementary treatment protocols. Abnormal capillary leakage, limbs pain, weakness and cramps are caused by HSP deficiency. Supplemental hesperidin also helps in reducing fluid exudation from capillaries [17]. HSP had antimutagenic activity [18], nerve health-promoting effects [19] and to protect against neurotoxicity [20]. 


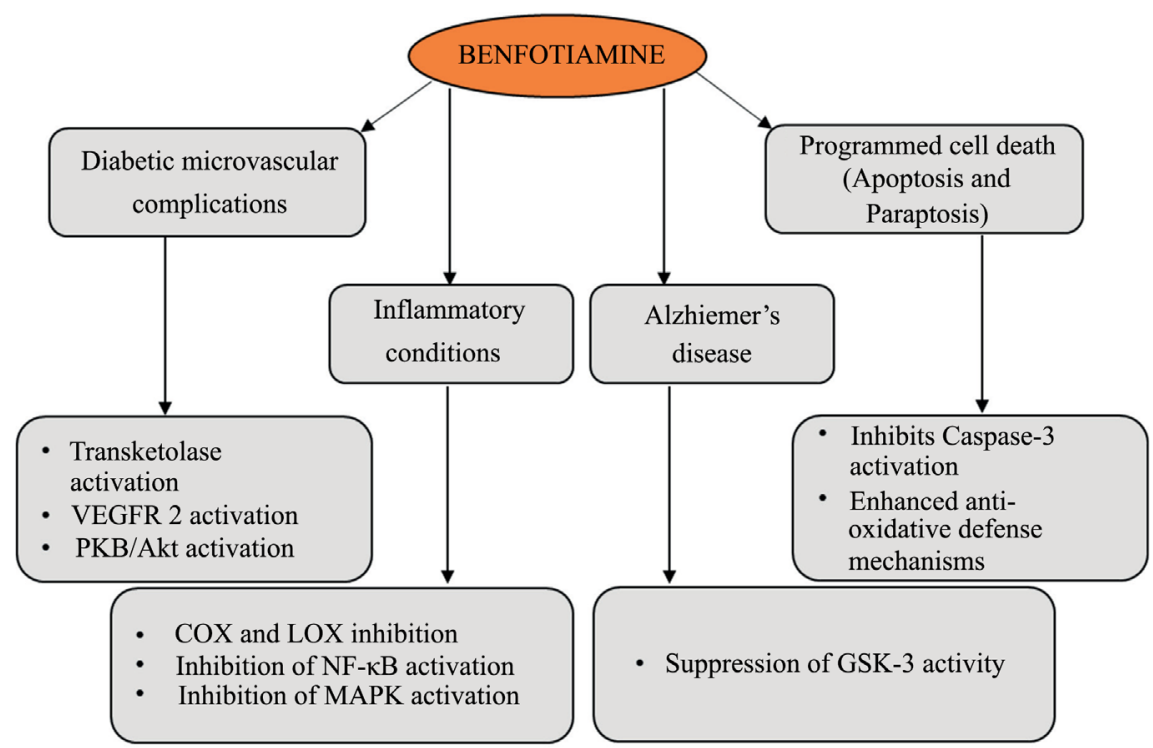

Figure 1. Role of benfotiamine in different conditions and its molecular targets.

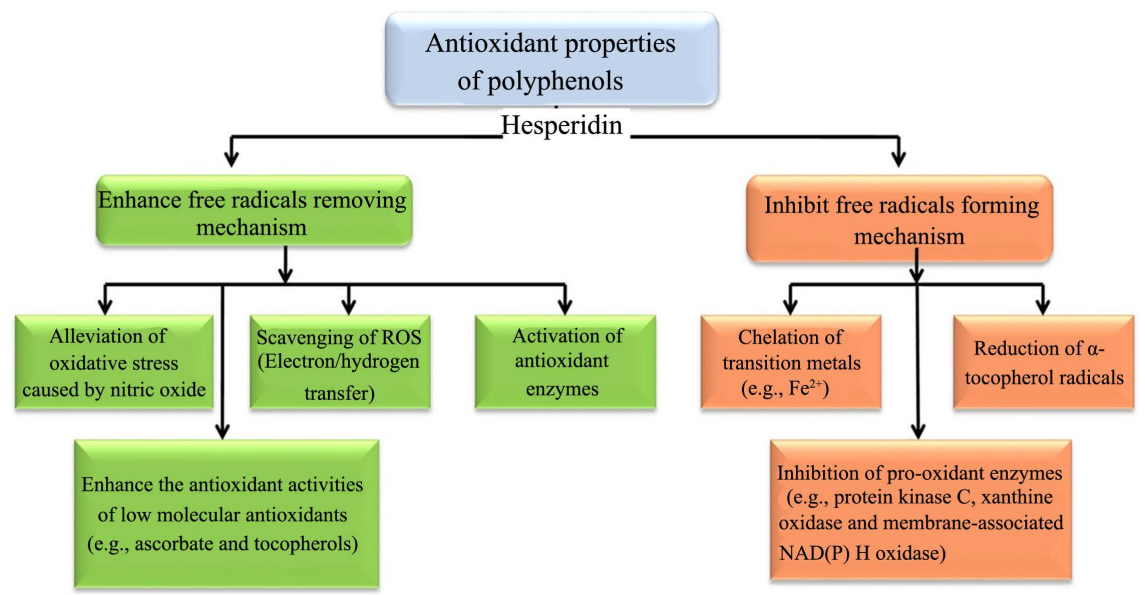

Figure 2. Role of hesperidin in different conditions.

Aim of this work is to compare the neuroprotective role of benfotiamine and hesperidin against paraquat produced biochemical, and histological changes in the spinal cord of adult albino rats.

\section{Ethics approval}

This study was approved by the local ethical committee of the Faculty of Medicine, Zagazig, Egypt.

\section{Material and Method}

\subsection{Chemicals}

\subsubsection{Paraquat}

It was ( $\geq 98 \%$ ) purchased from (St. Louis, MO, USA). was diluted in water.

\subsubsection{Benfotiamine}

It was purchased from Sigma-Aldrich, (MO, USA). 


\subsubsection{Hesperidin}

It was purchased from Sigma-Aldrich Chemical Company (St. Louis, MO, USA).

\subsubsection{Distilled Water}

As diluent to the paraquat and other chemicals.

\subsection{Kits}

\subsubsection{Oxidative Stress Markers (MDA, GSH, CAT Enzyme, SOD Enzyme, and GPx Enzyme)}

Kit was purchased from Bio diagnostic chemical company in Cairo.

\subsubsection{Phosphorylated Neurofilament-H (PNF-H)}

It was purchased from Sigma-Aldrich, (BioVendor Research and Diagnostic Product, Heidelberg, Germany).

\subsubsection{Neurospecific Enolase (NSE)}

It was purchased from Sigma-Aldrich (CanAg Diagnostics, Gothenburg, Sweden).

\subsection{4. $\mathrm{S} 100$}

It was purchased from Sigma-Aldrich (CanAg Diagnostics, Gothenburg, Sweden).

\subsection{Animals}

This study was carried on 40 adult male albino rats, each weighing 150 grams. The study had been designed in the Faculty of Medicine, Zagazig University. All animals received care in compliance with the Animal Care Guidelines and Ethical Regulations in accordance with "The Guide for the Care and Use of Laboratory Animals" (Institute of Laboratory Animal Resources (1996). In order to exclude fallacies, the following environmental conditions were standardized accordingly to Cuschier and Backer (1977).

1) The climate conditions in the animal house and in the cage free from any source of chemical contamination under room temperature $\left(22^{\circ} \mathrm{C} \pm 2^{\circ} \mathrm{C}\right)$, relative humidity $50 \% \pm 5 \%$ and a $12 \mathrm{~h}$ light cycle with free access to tap water with proper ventilation.

2) Intensity, quality, periodicity and duration of light were that of the natural light.

3) Bedding and wood shavings were usually kept in galvanized iron-mesh cages with solid bottoms that were changed frequently to keep the animal clean.

4) Overcrowding was avoided as well as isolation was avoided so, 10 rats per cage were put.

5) Low noise level was maintained as noise may affect the behaviour of the animals.

The rats were kept in this environment for two weeks before starting experimentation to be adapted to any possible stress secondary to transportation pro- 
cedure from the animal supplier or due to sudden environmental modification and exclude any diseased animals. The rats received balanced food, rich in all stuffs necessary to maintain their health before and during drug administration. It consists of ad libitum. Distilled water was offered in separate clean containers [21].

\section{Study Design}

The study was done for 4 weeks and the rats were randomly divided into 4 groups each of 10 rats. All chemicals are dissolved in $(1 \mathrm{ml})$ distilled water and are given once daily 6 days/week:

Group I (control group): Each rat received only regular diet and distilled water to determine the basic values of performance. These rats were left without intervention to measure the basic parameters.

Group II (paraquat group (PQ): Each rat was gavaged orally with 20.8 $\mathrm{mg} / \mathrm{kg} /$ day paraquat [22].

Group III (benfotiamine + paraquat group (BNF + PQ): Each rat was gavaged orally with $100 \mathrm{mg} / \mathrm{kg} /$ day benfotaimine [23]. was given 1 hour before paraquat that given in the previous doses and manner.

Group IV (hesperidin + paraquat group $(\mathrm{HSP}+\mathrm{PQ})$ : Each rat was gavaged orally with $40 \mathrm{mg} / \mathrm{kg}$ hesperidin [24]. was given 1 hour before paraquat that given in the previous doses and manner.

Oral administration was via appropriate sized metallic tube specific for gastric intubation of rats. Excess use of vehicle was avoided for fear of causing gastric distention, overflow or regurgitation that might lead to tracheal aspiration. One month injection in rats is equivalent to 24 months in human being [25].

\subsection{Methods}

- After 24 hours of the last administration, the rats were anesthetized with sodium pentobarbital ( $50 \mathrm{mg} / \mathrm{kg}$ body weight) by intraperitoneal injection. Blood samples were taken from retro-orbital plexuses into tubes containing EDTA for biochemical analysis, and then each rat was pinned to a dissecting board in a prone position. A midline incision was made from the neck to the sacral region [26]. Dead animals in each group were dissected, laminectomy was done and spinal cords were excised and examined for histopathological studies by light microscopy to know the underlying histopathological changes. The spinal cords specimens were fixed in Bouin's fixative, then processed to prepare 5-mm-thick paraffin sections, and stained with hematoxylin and eosin according to [27].

- The rat spine was harvested en bloc from the T11 vertebra to the L1 vertebra where the lumbar spinal cord located (Figure 3) (last rib was the land mark $=\mathrm{T} 13, \mathrm{~T} 13-\mathrm{L} 1$ vertebrae $=\mathrm{L} 4-\mathrm{L} 5$ spinal segments), then it was cleared of the paraspinal muscles and fixed in $10 \%$ neutral formalin then lateral laminectomy was done to each vertebra to clear lumbar spinal cord which post fixed in 10\% neutral formalin for histopathological examination [28]. 


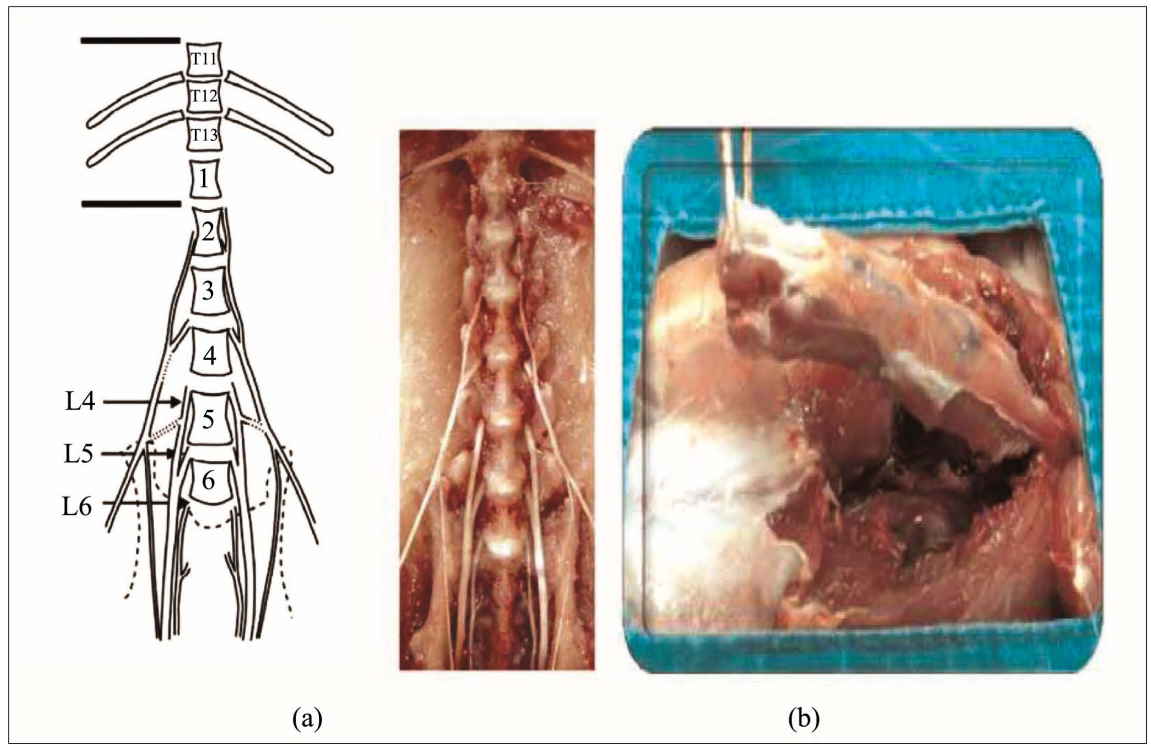

Figure 3. Dissection of the lumbar part of spinal cord. (a) The rat spine was dissected from the T11 vertebra to the L1 vertebra where the lumbar spinal cord located; (b) The rat spine was harvested en bloc [29].

\subsection{Biochemical Assays}

\subsubsection{Reduced Glutathione (GSH) Level in Spinal Cord}

This was determined by the method of Ellman [30] measuring yellow colour when 5,5-dithio-bis-2 nitro benzoic acid (DTNB) was added with spinal cords homogenates in phosphate buffer, then centrifuged. The absorbance was measured spectrophotometrically by ErbaChem 7 .

\subsubsection{Malonyldialdehyde (MDA) Level in Spinal Cord}

This was detected in the spinal cord homogenates by the method of Draper and Hadley [31] following the reaction of thiobarbituricacid (TBA) with malonyldialdehyde (MDA). The pink color produced was detected spectrophotometrically by ErbaChem 7.

\subsubsection{Antioxidant Enzyme Activities in Spinal Cord}

1) Catalase activity (CAT): This was detected following Aebi [32] by adding the homogenate hydrogen superoxide $\left(\mathrm{H}_{2} \mathrm{O}_{2}\right)$ with phosphate buffer; the changes in absorbance were recorded spectrophotometrically by ErbaChem 7 .

2) Superoxide dismutase activity (SOD): This was estimated according to Beauchamp and Fridovich [33] by adding potassium phosphate buffer, EDTA, L-methionine, riboflavin and nitro blue tetrazolium (NBT). Blue color in the reaction was measured spectrophotometrically by ErbaChem 7 .

3) Glutathione peroxidase activity (GPx): This was detected following Flohe and Günzler [34] procedure. The mixture of phosphate buffer, glutathione (GSH), sodium aside, and $\mathrm{H}_{2} \mathrm{O}_{2}$ and spinal cords homogenates was prepared. Tubes were centrifuged and the supernatant was collected. The absorbance was recorded spectrophotometrically by ErbaChem 7. 


\subsubsection{Serum Phosporylated Neurofilament-H (PNF-H) Levels}

Serum phosphorylated neurofilament-H (PNF-H) serum levels of rats in each group were analyzed using an enzyme-linked immunosorbent assay (ELISA), according to the manufacturer instructions. Detection limit is $23.5 \mathrm{pg} / \mathrm{ml}$, within- and inter run assay precision $<5 \%$ [35].

\subsubsection{Serum Neurospecific Enolase (NSE) Levels}

The levels of serum NSE were depended on 2 monoclonal antibodies processed against 2 separate antigenic determinants of the NSE molecule. The monoclonal antibodies unit to the subunit of the enzyme. NSE serum levels were measured by Enzyme Immunometric Assay (EIA) kit. The detection limit of the kit is (1 $150 \mu \mathrm{g} / \mathrm{L})[36]$.

\subsubsection{Serum S100 Levels}

The serum S100 levels were determined by a commercially available ELISA kit. The assay is depended on an antibody specific for the S100 dimer as catcher and HRP labeled monoclonal antibodies specific for S100 detection. The detection limit of this assay is $0.02 \mathrm{~g} / \mathrm{L}$ [37].

\subsubsection{Histopathological and Immunohistochemical Studies}

The lumbar part of the spinal cord of rats from all groups were excised and fixed in $10 \%$ neutral formalin, then dehydrated in $70 \%$ ethanol. Each lumbar spinal cord was then embedded in paraffin and subjected to the following:

\section{Histopathological evaluations}

Five $\mu \mathrm{m}$ sections were sectioned from the paraffin block and stained by hematoxylin and eosin then were examined under light microscope. The recommended technique was acorrding to Horobin and Bancroft [38].

\section{Immunohistochemical evaluations}

Immunostaining was done on serial sections, $4 \mu \mathrm{m}$ in thickness were cut on slides. The tissue sections were deparaffinized in xylene and rehydrated in graded ethanol. Deparaffinized tissue sections were emersed in hydrogen peroxide for $10 \mathrm{~min}$ to inhibit non-specific peroxidase reaction. Microwave antigen retrieval was processed for $20 \mathrm{~min}$ in citrate buffer $0.01 \mathrm{M}$ (pH 6.0). After washing with PBS, the slides were incubated for $60 \mathrm{~min}$ at room temperature with monoclonal antibodies (primary antisera against nitrotyrosine); Anti-3-Nitrotyrosine antibody ([39B6] ab61392, dilution 1:200, abcam, UK). Binding site of primary antibodies was visualized by using the Dako EnVision ${ }^{\mathrm{TM}}$ kit (Dako, Copenhagen, Denmark). Then, the sections were counterstained with Mayer's hematoxylin [39].

\section{Method of evaluation of IHC results}

Qualitative interpretation of IHC data was used as a method of evaluation as identified by Zimmermann et al. [40]. The spectrum of categories describing different force of IHC expression in investigated groups include: negative (-), weak $(+)$, moderate $(++)$ and strong $(+++)$.

The biochemical and IHC results of the present study have been tabulated and 
themed to statistical analysis.

\section{Statestical analysis}

The collected data were expressed as Mean \pm SD. The statistical analysis was performed using a commercial software package (SPSS version 20 for Windows). The data were presented by means and the following tests were used: Arithmetic mean (X) and Standard deviation (SD). Student $t$ test was used for comparison between means Level of significance. Significance was set at $\mathrm{P}$ value less than 0.05 for all comparisons.

\section{Results}

\subsection{Biochemical Results}

\subsubsection{Reduced Glutathione (GSH) Level in Spinal Cord}

There was highly significant decrease of spinal cord tissue (GSH) content in (PQ) treated rats group when compared with the control, (BNF + PQ) and (HSP $+\mathrm{PQ}$ ) groups (Table 1, Table 4, Table 5). There was non-significant difference of spinal cord tissue $(\mathrm{GSH})$ content in $(\mathrm{BNF}+\mathrm{PQ})$ treated rats group when compared with the (HSP + PQ) group (Table 6). There was non-significant difference of spinal cord tissue (GSH) content in (BNF + PQ) and (HSP + PQ) treated rats group when compared with the control group (Table 2, Table 3 ).

\subsubsection{Malonyldialdehyde (MDA) Level in Spinal Cord}

There was highly significant increase of spinal cord tissue (MDA) content in (PQ) treated rats group when compared with the control, (BNF + PQ) and (HSP + PQ) groups (Table 1, Table 4, Table 5). There was non-significant difference of spinal cord tissue (MDA) content in $(\mathrm{BNF}+\mathrm{PQ})$ treated rats group when

Table 1. A statistical comparison between (control group "I" and PQ treated group "II") as regard mean values of as regard mean values of glutathione peroxidase and malonyldialdehydeby t-test.

\begin{tabular}{|c|c|c|c|}
\hline Parametrs & $\begin{array}{c}\text { Control } \\
\text { Group } \\
\text { Mean } \pm \text { SD }\end{array}$ & $\begin{array}{c}\text { PQ } \\
\text { Group } \\
\text { Mean } \pm \text { SD }\end{array}$ & $\mathrm{p}$ \\
\hline Reduced glutathione (mg/g) & $235.00 \pm 2.27$ & $162.17 \pm 2.37$ & $<0.001^{* *}$ \\
\hline Malonyldialdehyde (nmol/g) & $28.35 \pm 0.69$ & $63.7 \pm 3.93$ & $<0.001^{* *}$ \\
\hline
\end{tabular}

$\mathrm{SD}=$ Standard deviation; N.B: ${ }^{*}=$ highly significant; $\mathrm{PQ}=$ paraquat. $\mathrm{t}$ test $=$ student's $\mathrm{t}$-test.

Table 2. A statistical comparison between (control group "I" and BNF + PQ treated group "III") as regard mean values of as regard mean values of glutathione peroxidase and malonyldialdehydeby t-test.

\begin{tabular}{|c|c|c|c|}
\hline Parametrs & $\begin{array}{c}\text { Control } \\
\text { Group } \\
\text { Mean } \pm \text { SD }\end{array}$ & $\begin{array}{c}\mathrm{BNF}+\mathrm{PQ} \\
\text { Group } \\
\text { Mean } \pm \mathrm{SD}\end{array}$ & $\mathrm{p}$ \\
\hline Reduced glutathione (mg/g) & $235.00 \pm 2.27$ & $232.16 \pm 3.39$ & $0.10 \#$ \\
\hline Malonyldialdehyde (nmol/g) & $28.35 \pm 0.69$ & $30.85 \pm 2.57$ & $0.78 \#$ \\
\hline
\end{tabular}

$\mathrm{SD}=$ Standard deviation; N.B: $\#=$ non significant; $\mathrm{PQ}=$ paraquat; $\mathrm{BNF}=$ benfotiamine. $\mathrm{t}$ test $=$ student's $\mathrm{t}$-test. 
Table 3. A statistical comparison between (control group "I" and HSP + PQ treated group "IV") as regard mean values of as regard mean values of glutathione peroxidase and malonyldialdehydeby t-test.

\begin{tabular}{cccc}
\hline Group & $\begin{array}{c}\text { Control } \\
\text { Group } \\
\text { Parametrs }\end{array}$ & $\begin{array}{c}\text { HSP + PQ } \\
\text { Group } \\
\text { Mean } \pm \text { SD }\end{array}$ & P \\
\hline Reduced glutathione $(\mathrm{mg} / \mathrm{g})$ & $235.00 \pm 2.27$ & $232.70 \pm 2.54$ & $0.12 \#$ \\
Malonyldialdehyde $(\mathrm{nmol} / \mathrm{g})$ & $28.35 \pm 0.69$ & $28.35 \pm 0.69$ & $0.25 \#$ \\
\hline
\end{tabular}

$\mathrm{SD}=$ Standard deviation; N.B: \# = non significant; $\mathrm{PQ}=$ paraquat; $\mathrm{HSP}=$ hesperidin. $\mathrm{t}$ test $=$ student's $\mathrm{t}$-test.

Table 4. A statistical comparison between (PQ group "II" and BNF + PQ treated group "III") as regard mean values of as regard mean values of glutathione peroxidase and malonyldialdehydeby t-test.

\begin{tabular}{cccc}
\hline Group & $\begin{array}{c}\text { PQ } \\
\text { Group } \\
\text { Parametrs }\end{array}$ & $\begin{array}{c}\text { BNF + PQ } \\
\text { Group } \pm \text { SD } \\
\text { Mean } \pm \text { SD }\end{array}$ & P \\
\hline Reduced glutation $(\mathrm{mg} / \mathrm{g})$ & $162.17 \pm 2.37$ & $232.16 \pm 3.39$ & $<0.001^{\star *}$ \\
Malonyldialdehyde $(\mathrm{nmol} / \mathrm{g})$ & $63.7 \pm 3.93$ & $30.85 \pm 2.57$ & $<0.001^{\star *}$ \\
\hline
\end{tabular}

$\mathrm{SD}=$ Standard deviation; N.B: ${ }^{*}=$ highly significant; $\mathrm{PQ}=$ paraquat; $\mathrm{BNF}=$ benfotiamine. $\mathrm{t}$ test $=$ student's $\mathrm{t}$-test.

Table 5. A statistical comparison between (PQ group "II" and HSP + PQ treated group "IV") as regard mean values of as regard mean values of glutathione peroxidase and malonyldialdehydeby t-test.

\begin{tabular}{|c|c|c|c|}
\hline Parametrs & $\begin{array}{c}\text { PQ } \\
\text { Group } \\
\text { Mean } \pm \text { SD }\end{array}$ & $\begin{array}{c}\text { HSP + PQ } \\
\text { Group } \\
\text { Mean } \pm \text { SD }\end{array}$ & $\mathrm{p}$ \\
\hline Reduced glutathione (mg/g) & $162.17 \pm 2.37$ & $232.70 \pm 2.54$ & $<0.001^{\star *}$ \\
\hline Malonyldialdehyde (nmol/g) & $63.7 \pm 3.93$ & $28.35 \pm 0.69$ & $<0.001^{\star *}$ \\
\hline
\end{tabular}

$\mathrm{SD}=$ Standard deviation; N.B: ${ }^{* *}=$ highly significant; $\mathrm{PQ}=$ paraquat; HSP $=$ hesperidin. $\mathrm{t}$ test $=$ student's $\mathrm{t}$-test.

compared with the (HSP + PQ) group (Table 6). There was non-significant difference of spinal cord tissue (MDA) content in (BNF + PQ) and (HSP + PQ) treated rats group when compared with the control group (Table 2, Table 3).

\subsubsection{Antioxidant Enzyme Activities}

Spinal cord antioxidant enzyme activities significantly decreased in the (PQ) treated group as compared to the control, $(\mathrm{BNF}+\mathrm{PQ})$, and (HSP + PQ) groups, in the activities of (CAT) (Figure 4), (SOD) (Figure 5) and (GPx) (Figure 6) in spinal cord homogenates of rats.

\subsubsection{Serum Phosporylated Neurofilament-H (PNF-H) Levels}

When serum PNF-H mean values of the PQ treated group "II" compared to group "I", BNF + PQ group "III", and HSP + PQ group “IV", showed a highly significant increase after 4 weeks of PQ treatment $(\mathrm{P}<0.001)$ (Table 7, Table 10, Table 11). 


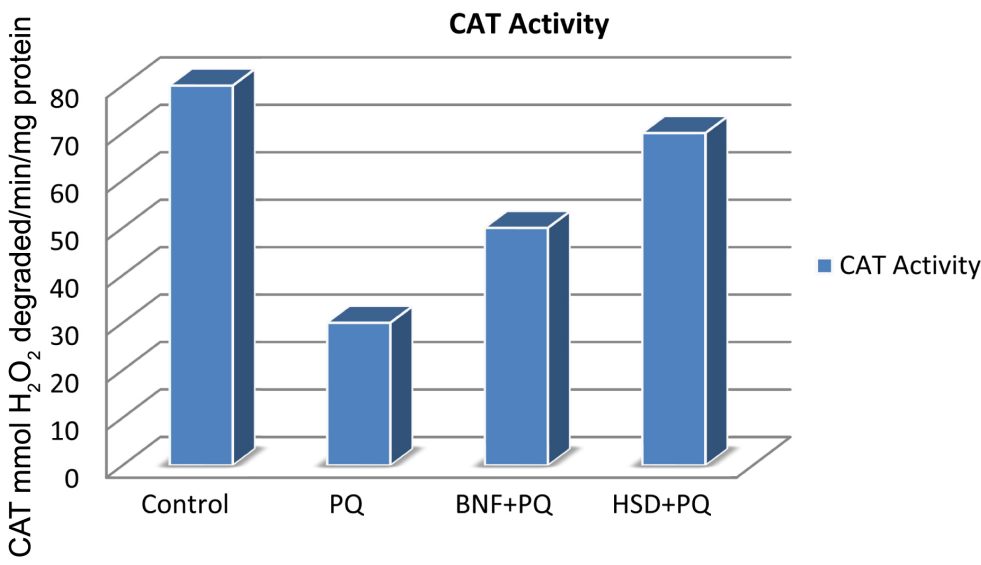

Figure 4. Bar chart showing comparative magnitude of activity of catalase enzymes (CAT) at different groups: control, paraquat $(\mathrm{PQ})$, benfotaimine + paraquat $(\mathrm{BNF}+\mathrm{PQ})$ and hesperdin + paraquat $(\mathrm{HSD}+\mathrm{PQ})$ treated groups after 4 weeks of the study.

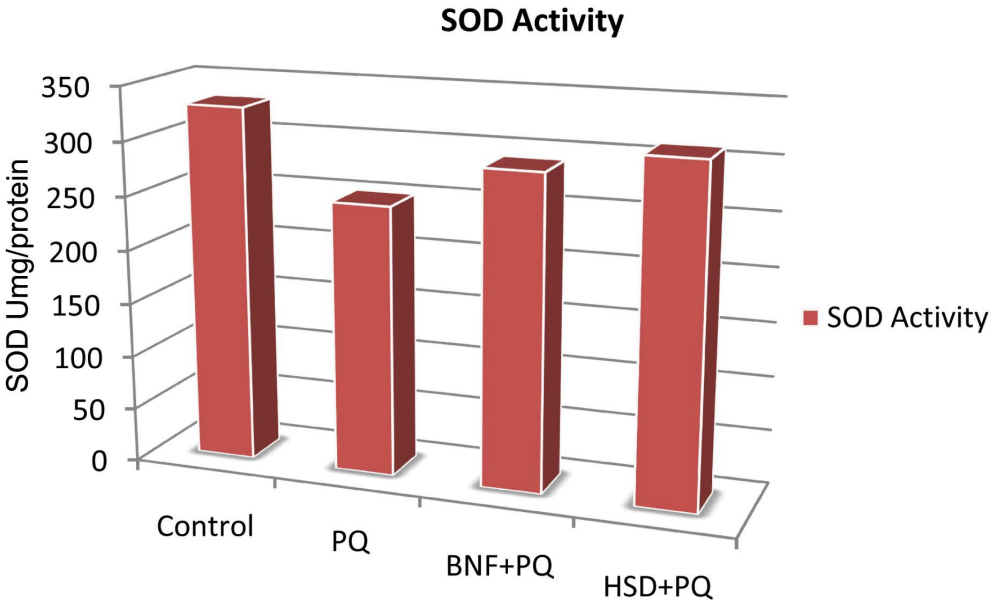

Figure 5. Bar chart showing comparative magnitude of activity of superoxide dismutase enzyme (SOD) at different groups: control, paraquat (PQ), benfotaimine + paraquat (BNF $+\mathrm{PQ})$ and hesperdin + paraquat $(\mathrm{HSD}+\mathrm{PQ})$ treated groups after 4 weeks of the study.

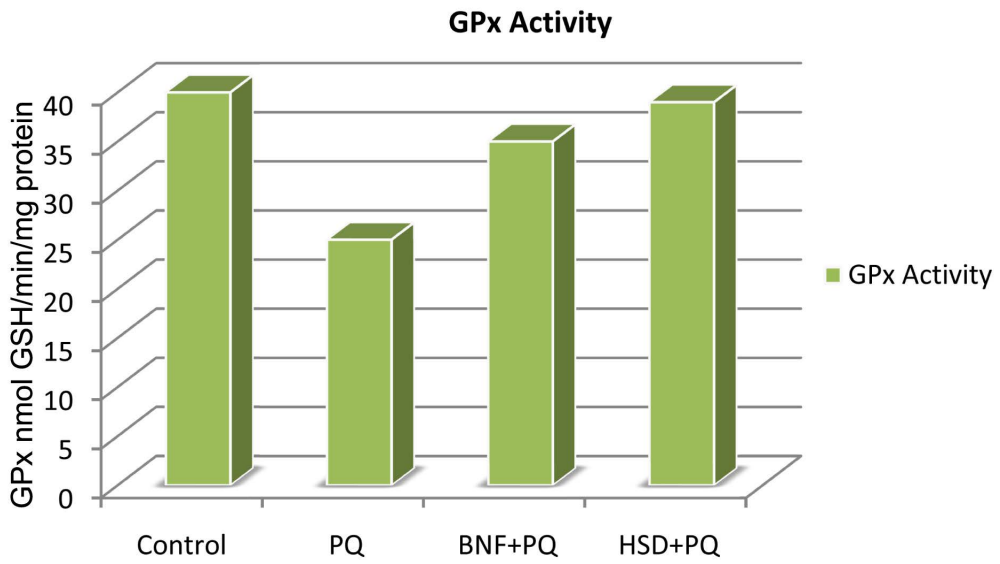

Figure 6. Bar chart showing comparative magnitude of activity of glutathione peroxidase enzyme (GPx) at different groups: control, paraquat (PQ), benfotaimine + paraquat (BNF $+\mathrm{PQ})$ and hesperdin + paraquat (HSD + PQ) treated groups after 4 weeks of the study. 
Table 6. A statistical comparison between (BNF + PQ group "III" and HSP + PQ treated group "IV") as regard mean values of as regard mean values of glutathione peroxidase and malonyldialdehydeby t-test.

\begin{tabular}{lccl}
\hline Group & $\begin{array}{c}\text { BNF }+ \text { PQ } \\
\text { Group } \\
\text { Mean } \pm \text { SD }\end{array}$ & $\begin{array}{c}\text { HSP }+ \text { PQ } \\
\text { Group } \\
\text { Mean } \pm \text { SD }\end{array}$ & p \\
\hline Reduced glutathione $(\mathrm{mg} / \mathrm{g})$ & $232.16 \pm 3.39$ & $232.70 \pm 2.54$ & $0.41 \#$ \\
Malonyldialdehyde $(\mathrm{nmol} / \mathrm{g})$ & $30.85 \pm 2.57$ & $28.35 \pm 0.69$ & $0.11 \#$ \\
\hline
\end{tabular}

$\mathrm{SD}=$ Standard deviation; N.B: \# = non significant; $\mathrm{PQ}=$ paraquat; $\mathrm{BNF}=$ benfotiamine; $\mathrm{HSP}=$ hesperidin . $\mathrm{t}$ test $=$ student's $\mathrm{t}$-test.

Table 7. A statistical comparison between (control group "I" and PQ treated group "II") as regard mean values of serum biochemical parameters by $\mathrm{t}$-test.

\begin{tabular}{cccc}
\hline \multicolumn{1}{c}{ Group } & $\begin{array}{c}\text { Control } \\
\text { Group } \\
\text { Mean } \pm \text { SD }\end{array}$ & $\begin{array}{c}\text { PQ } \\
\text { Group } \\
\text { Mean } \pm \text { SD }\end{array}$ & p \\
\hline $\begin{array}{c}\text { Serum phosporylated neurofilament-H (PNF-H) } \\
(\mathrm{ng} / \mathrm{ml})\end{array}$ & $0.49 \pm 0.04$ & $6.19 \pm 0.20$ & $<0.001^{* *}$ \\
Serum Neurospecific enolase (NSE) \\
$\begin{array}{c}(\mu \mathrm{g} / \mathrm{L}) \\
\text { Serum S100 levels } \\
(\mu \mathrm{g} / \mathrm{L})\end{array}$ & $8.54 \pm 0.32$ & $31.55 \pm 0.86$ & $<0.001^{* *}$ \\
& $0.095 \pm 0.003$ & $0.353 \pm 0.036$ & $<0.001^{* *}$
\end{tabular}

$\mathrm{SD}=$ Standard deviation; N.B: ${ }^{*}=$ highly significant; $\mathrm{PQ}=$ paraquat. $\mathrm{t}$ test $=$ student's $\mathrm{t}$-test.

When serum PNF-H mean values of BNF + PQ treated group "III" compared to group I, there was non-significant difference along the duration of the study $(\mathrm{P}<0.05)$ (Table 8).

When serum PNF-H mean values of the HSP + PQ treated group "IV" compared to group "I", showed non-significant difference after 4 weeks of HSP with $P Q$ treatment $(\mathrm{P}<0.001)$ (Table 9).

When serum PNF-H mean values of the HSP + PQ treated group "IV" compared to BNF + PQ group "III", showed non-significant difference after 4 weeks of HSP with PQ treatment $(\mathrm{P}<0.001)$ (Table 12).

\subsubsection{Serum Neurospecific Enolase (NSE) Levels}

When serum NSE mean values of the PQ treated group "II" compared to group "I", BNF + PQ group "III", and HSP + PQ group"IV", showed a highly significant increase after 4 weeks of $P Q$ treatment $(P<0.001)$ (Table 7, Table 10, Table 11).

When serum NSE mean values of BNF + PQ treated group "III", compared to group I, there was non-significant difference along the duration of the study $(\mathrm{P}<$ 0.05) (Table 8).

When serum NSE mean values of the HSP + PQ treated group "IV" compared to group "I", showed non-significant difference after 4 weeks of HSP with PQ treatment $(\mathrm{P}<0.001)$ (Table 9). 
Table 8. A statistical comparison between (control group "I" and BNF + PQ treated group "III") as regard mean values of serum biochemical parameters by t-test.

\begin{tabular}{cccc}
\hline \multicolumn{1}{c}{ Group } & $\begin{array}{c}\text { Control } \\
\text { Group } \\
\text { Pean } \pm \text { SD }\end{array}$ & $\begin{array}{c}\text { BNF }+ \text { PQ } \\
\text { Group } \\
\text { Mean } \pm \text { SD }\end{array}$ & p \\
\hline $\begin{array}{c}\text { Serum phosporylated neurofilament-H (PNF-H) } \\
(\mathrm{ng} / \mathrm{ml})\end{array}$ & $0.49 \pm 0.04$ & $0.53 \pm 0.06$ & $0.20 \#$ \\
$\begin{array}{c}\text { Serum Neurospecific enolase (NSE) } \\
(\mu \mathrm{g} / \mathrm{L})\end{array}$ & $8.54 \pm 0.32$ & $8.63 \pm 0.55$ & $0.40 \#$ \\
$\quad \begin{array}{c}\text { Serum S100 levels } \\
(\mu \mathrm{g} / \mathrm{L})\end{array}$ & $0.095 \pm 0.003$ & $0.102 \pm 0.005$ & $0.07 \#$ \\
\hline
\end{tabular}

$\mathrm{SD}=$ Standard deviation; N.B: $\#=$ non significant; $\mathrm{PQ}=$ paraquat; $\mathrm{BNF}=$ benfotiamine. $\mathrm{t}$ test $=$ student's t-test .

Table 9. A statistical comparison between (control group "I" and HSP + PQ treated group "IV") as regard mean values of serum biochemical parameters by t-test.

\begin{tabular}{cccc}
\hline \multicolumn{1}{c}{ Group } & $\begin{array}{c}\text { Control } \\
\text { Group } \\
\text { Pean } \pm \text { SD }\end{array}$ & $\begin{array}{c}\text { HSP }+ \text { PQ } \\
\text { Group } \\
\text { Mean } \pm \text { SD }\end{array}$ & p \\
\hline $\begin{array}{c}\text { Serum phosporylated neurofilament-H (PNF-H) } \\
(\mathrm{ng} / \mathrm{ml})\end{array}$ & $0.49 \pm 0.04$ & $0.55 \pm 0.08$ & $0.13 \#$ \\
$\begin{array}{c}\quad \begin{array}{c}\text { Serum Neurospecific enolase (NSE) } \\
(\mu \mathrm{g} / \mathrm{L})\end{array} \\
\begin{array}{c}\text { Serum } \mathrm{S} 100 \text { levels } \\
(\mu \mathrm{g} / \mathrm{L})\end{array}\end{array}$ & $8.54 \pm 0.32$ & $9.61 \pm 1.22$ & $0.09 \#$ \\
\hline
\end{tabular}

$\mathrm{SD}=$ Standard deviation; N.B: \# = non significant; $\mathrm{PQ}=$ paraquat; $\mathrm{HSP}=$ hesperidin. $\mathrm{t}$ test $=$ student's $\mathrm{t}$-test.

Table 10. A statistical comparison between (PQ group "II" and BNF + PQ treated group "III") as regard mean values of serum biochemical parameters by t-test.

\begin{tabular}{|c|c|c|c|}
\hline Parametrs & $\begin{array}{c}\text { PQ } \\
\text { Group } \\
\text { Mean } \pm \text { SD }\end{array}$ & $\begin{array}{c}\mathrm{BNF}+\mathrm{PQ} \\
\text { Group } \\
\text { Mean } \pm \mathrm{SD}\end{array}$ & $\mathrm{p}$ \\
\hline $\begin{array}{l}\text { Serum phosporylated neurofilament-H (PNF-H) } \\
\qquad(\mathrm{ng} / \mathrm{ml})\end{array}$ & $6.19 \pm 0.20$ & $0.53 \pm 0.06$ & $<0.001^{\star *}$ \\
\hline $\begin{array}{l}\text { Serum Neurospecific enolase (NSE) } \\
(\mu \mathrm{g} / \mathrm{L})\end{array}$ & $31.55 \pm 0.86$ & $8.63 \pm 0.55$ & $<0.001^{* *}$ \\
\hline $\begin{array}{c}\text { Serum } S 100 \text { levels } \\
(\mu \mathrm{g} / \mathrm{L})\end{array}$ & $0.353 \pm 0.036$ & $0.102 \pm 0.005$ & $<0.001^{\star *}$ \\
\hline
\end{tabular}

$\mathrm{SD}=$ Standard deviation; N.B: ${ }^{* *}=$ highly significant; $\mathrm{PQ}=$ paraquat; $\mathrm{BNF}=$ benfotiamine. $\mathrm{t}$ test $=$ student's t-test.

Table 11. A statistical comparison between (PQ group "II" and HSP + PQ treated group "IV") as regard mean values of serum biochemical parameters by t-test.

\begin{tabular}{|c|c|c|c|}
\hline Parametrs & $\begin{array}{c}\text { PQ } \\
\text { Group } \\
\text { Mean } \pm \text { SD }\end{array}$ & $\begin{array}{c}\text { HSP + PQ } \\
\text { Group } \\
\text { Mean } \pm \text { SD }\end{array}$ & $\mathrm{p}$ \\
\hline $\begin{array}{l}\text { Serum phosporylated neurofilament-H (PNF-H) } \\
\qquad(\mathrm{ng} / \mathrm{ml})\end{array}$ & $6.19 \pm 0.20$ & $0.55 \pm 0.08$ & $<0.001^{\star *}$ \\
\hline $\begin{array}{l}\text { Serum Neurospecific enolase (NSE) } \\
(\mu \mathrm{g} / \mathrm{L})\end{array}$ & $31.55 \pm 0.86$ & $9.61 \pm 1.22$ & $<0.001^{* *}$ \\
\hline $\begin{array}{l}\text { Serum S100 levels } \\
\qquad(\mu \mathrm{g} / \mathrm{L})\end{array}$ & $0.353 \pm 0.036$ & $0.100 \pm 0.007$ & $<0.001^{\star *}$ \\
\hline
\end{tabular}


When serum NSE mean values of the HSP + PQ treated group "IV" compared to BNF + PQ group "III", there was non-significant difference along the duration of the study $(\mathrm{P}<0.05)$ (Table 12).

\subsubsection{Serum S100 Levels}

When serum S100 mean values of the PQ treated group "II" compared to group "I", BNF + PQ group "III", and HSP + PQ group "IV", showed a highly significant increase after 4 weeks of $P Q$ treatment $(\mathrm{P}<0.001)$ (Table 7, Table 10, Table 11).

When serum S100 mean values of BNF + PQ treated group "III" compared to group I, there was non-significant difference along the duration of the study $(\mathrm{P}<$ 0.05) (Table 8).

When serum S100 mean values of the HSP + PQ treated group "IV" compared to group "I", there was non-significant difference along the duration of the study $(\mathrm{P}<0.05)$ (Table 9).

When serum S100 mean values of the HSP + PQ treated group "IV" compared to BNF + PQ group "III", there was non-significant difference along the duration of the study $(\mathrm{P}<0.05)$ (Table 12).

\subsubsection{Histopathological Changes of the Spinal Cord \\ Macroscopic examination}

Showed the spinal cord of both control and treated groups revealed normal appearance with no significant changes in size, any cystic changes or abnormal masses. Cut sections were normal.

\section{Light microscopic examination}

\section{Control group}

Hematoxylin and eosin-stained sections showed normal histological structure of the spinal cord including apparent increase in number and size of basophilic differentiated motor neurons, decrease in different form of neuroglia and scattered small capillaries (Figure 7).

Paraquat group

Table 12. A statistical comparison between (BFM + PQ group "III" and HSP + PQ treated group "IV") as regard mean values of serum biochemical parameters by t-test.

\begin{tabular}{cccc}
\hline Group & $\begin{array}{c}\text { BNF }+ \text { PQ } \\
\text { Group } \\
\text { Mean } \pm \text { SD }\end{array}$ & $\begin{array}{c}\text { HSP }+ \text { PQ } \\
\text { Group } \\
\text { Mean } \pm \text { SD }\end{array}$ & p \\
\hline $\begin{array}{c}\text { Serum phosporylated neurofilament-H (PNF-H) } \\
(\mathrm{ng} / \mathrm{ml})\end{array}$ & $0.53 \pm 0.06$ & $0.55 \pm 0.08$ & $0.34 \#$ \\
$\quad \begin{array}{c}\text { Serum Neurospecific enolase (NSE) } \\
(\mu \mathrm{g} / \mathrm{L})\end{array}$ & $8.63 \pm 0.55$ & $9.61 \pm 1.22$ & $0.12 \#$ \\
$\quad \begin{array}{c}\text { Serum } \mathrm{S100} \text { levels } \\
(\mu \mathrm{g} / \mathrm{L})\end{array}$ & $0.102 \pm 0.005$ & $0.100 \pm 0.007$ & $0.35 \#$ \\
\hline
\end{tabular}

$\mathrm{SD}=$ Standard deviation; N.B: \# = non significant; $\mathrm{PQ}=$ paraquat; $\mathrm{BNF}=$ benfotiamine; $\mathrm{HSP}=$ hesperidin. $\mathrm{t}$ test $=$ student's t-test. 


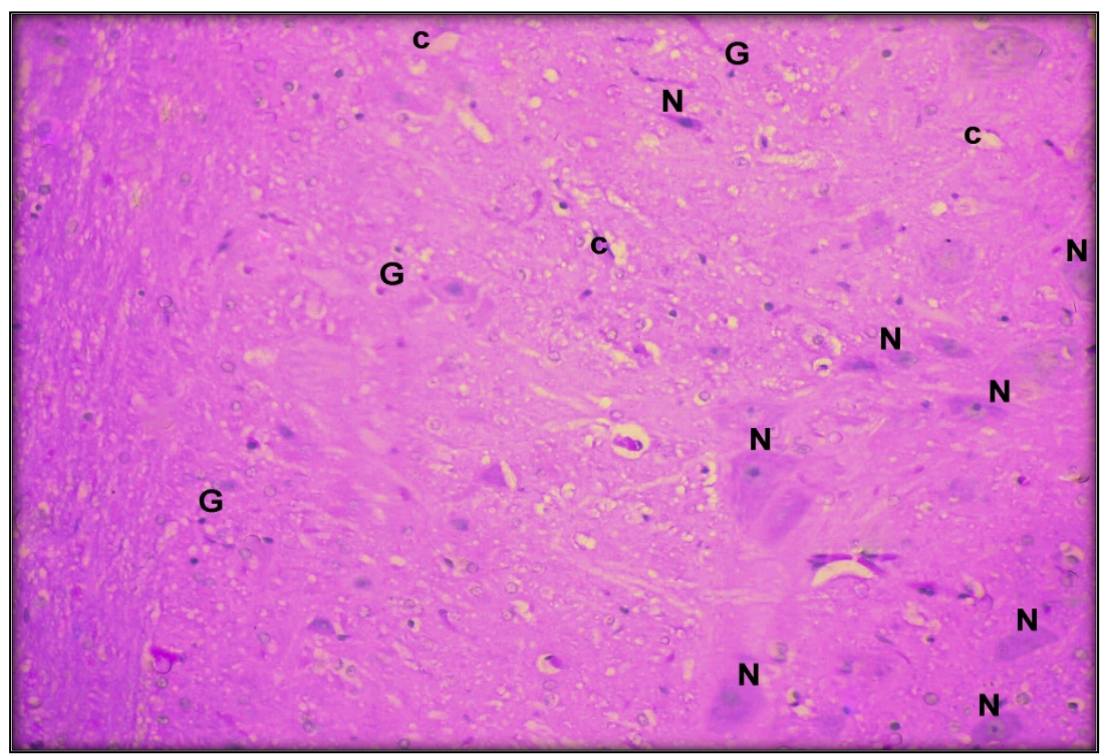

Figure 7. Spinal cord transverse section (lumbar anterior horn) in Control rat shows increase in number and size of basophilic differentiated motor neurons $(\mathrm{N})$, decrease in different form of neuroglia (G) and scattered small capillaries (C) H \& E (×400).

Haematoxylin and eosin-stained sections showed decrease in differentiated and increase in degenerated neurons (eosinophilic, pyknotic). In addition to, neuropil hemorrhage, vacuolation neuropil, dilated congested capillaries, and neurogliosis (Figure 8).

Benfotaimine and paraquat group

Hematoxylin and eosin-stained sections showed near normal appearance of the control group sections with few vacuolation, degenerated neurons and dilated congested capillaries (Figure 9).

Hesperidin and paraquat group

Haematoxylin and eosin-stained sections showed near normal appearance of the control group sections with few vacuolation, degenerated neurons and dilated congested capillaries (Figure 9).

Treatment with benfotaimine and hesperidin statistically reduced the pathological lesions caused by paraquat $\left(\mathrm{P}<0.001^{* *}\right)$ (Table 13).

\section{Immunohistochemical examination}

Nitrotyrosine cytoplasmic immunostaining was detected exclusively in the of neurons. In control group, low proportion of nitotyrosine-positive neurons and low morphologic alterations were observed (Figure 10).

In paraquate group, many nitrotyrosine-positive neurons were found (Figure $11)$.

Benfotaimine + paraquate and hesperidin + paraquate treated groups showed low proportion of nitotyrosine-positive neurons (Figure 12). The distribution of nitrotyrosine immunohistochemical reactivity within rat tissues were negatively, moderately and strongly correlated with histologic and morphologic alterations affecting neurons appeared scattered, patchy, and diffuse. 


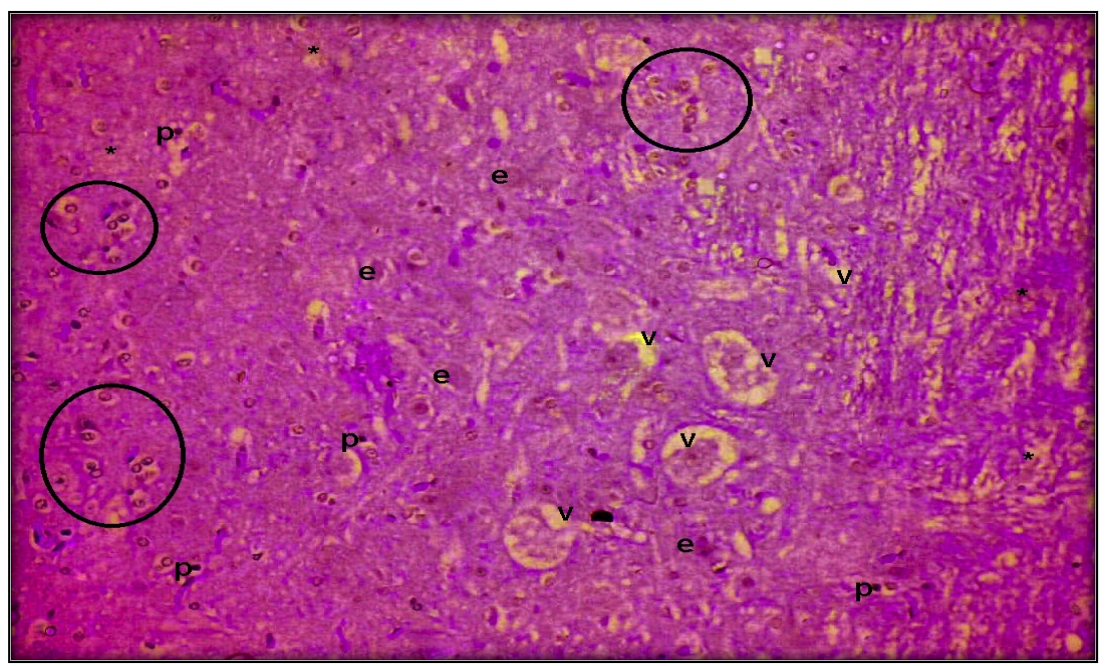

Figure 8. Spinal cord transverse section (lumbar anterior horn) in paraquat treated rat shows decrease in differentiated and increase in degenerated neurons (eosinophilic [e], pyknotic [p]), neuropil hemorrhage $\left(^{\star}\right)$ vacuolation neuropil $(v)$, dilated congested capillaries, and neurogliosis (circle) H \& E $(\times 400)$.

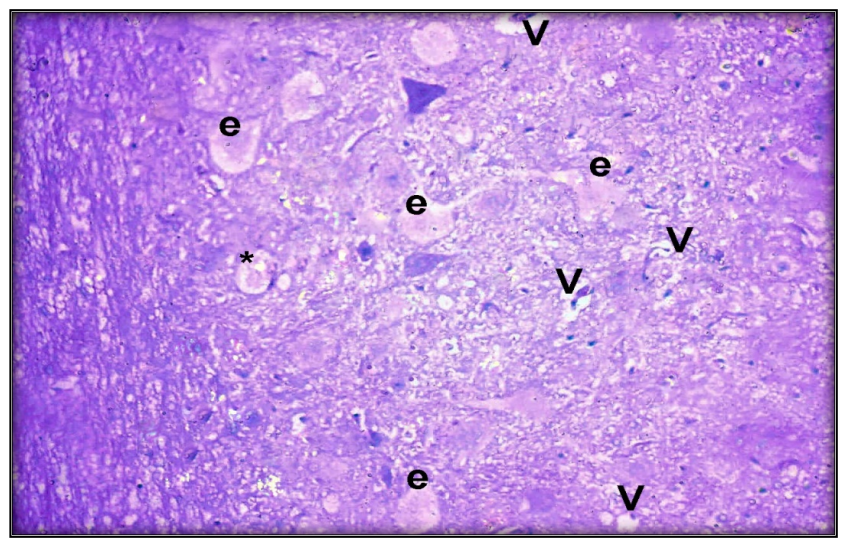

Figure 9. Spinal cord transverse section (lumbar anterior horn) in benfotaimine or hesperidin with paraquat treated rats shows similar picture to that of the control with few vacuolation (v), degenerated neurons (e) and dilated congested capillaries $\left({ }^{*}\right) \mathrm{H} \& \mathrm{E}(\times 400)$.

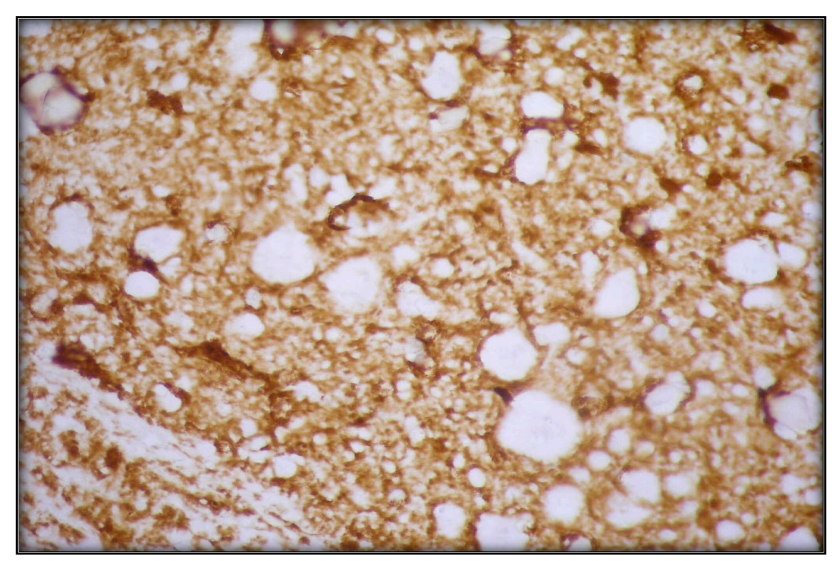

Figure 10. Spinal cord transverse section (lumbar anterior horn) in control rats Negative nitrotyrosine immunoreactivity is observed in neurons $(\times 400)$. 


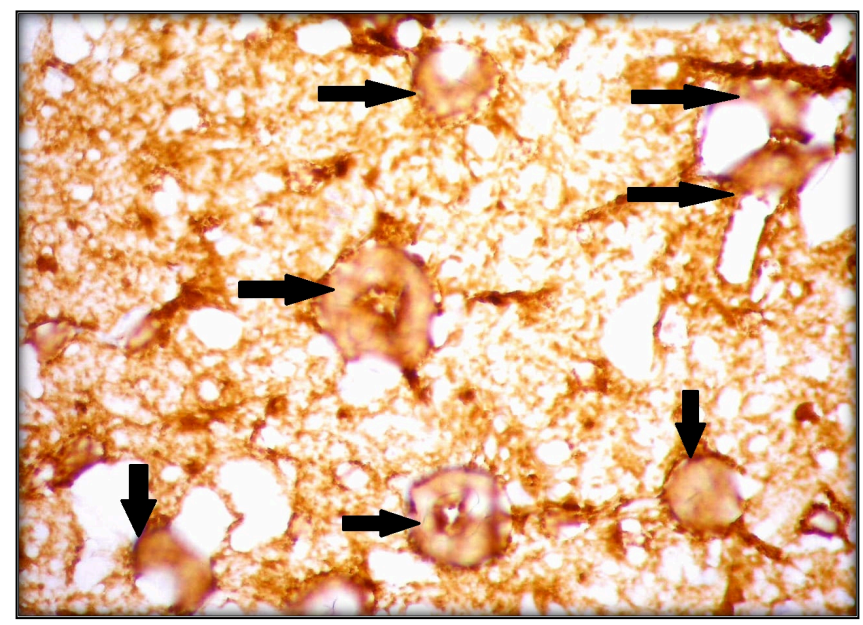

Figure 11. Spinal cord transverse section (lumbar anterior horn) in paraquat treated rats shows positive strong Nitrotyrosine immunoreactivity is observed in the degenerated anterior horn neuron and reactive astrocytes show positive nitrotyrosine immunoreactivity $(\times 400)$.

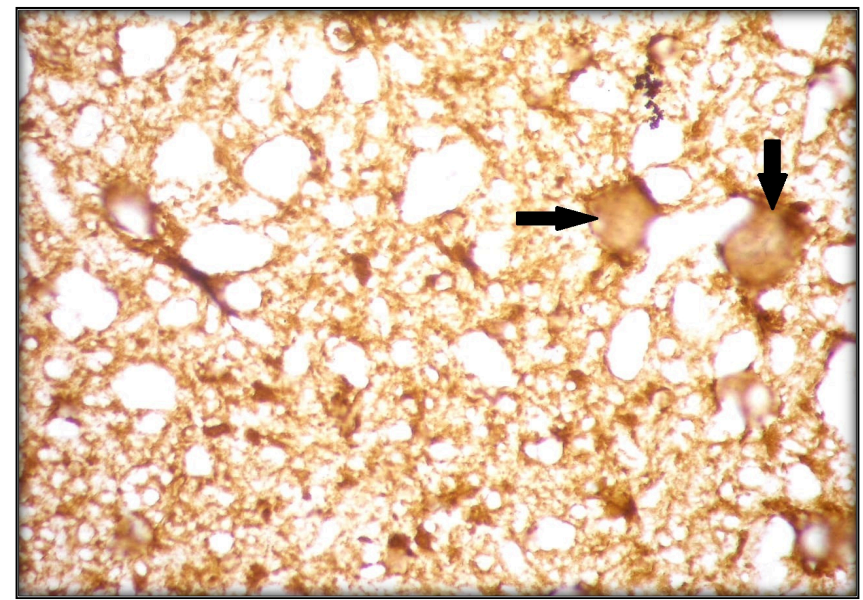

Figure 12. Spinal cord transverse section (lumbar anterior horn) in benfotaimine or hesperidin with paraquat treated rats shows positive moderate Nitrotyrosine immunoreactivity is observed in the degenerated neuron and reactive astrocytes show positive nitrotyrosine immunoreactivity $(\times 400)$.

Table 13. Chi-square test statistical analysis of pathological changes in spinal cord of different groups.

\begin{tabular}{|c|c|c|c|c|c|c|}
\hline \multirow[t]{2}{*}{ Group } & $\begin{array}{l}\text { Control } \\
(\mathrm{N}=10)\end{array}$ & $\begin{array}{c}P Q \\
(N=10)\end{array}$ & $\begin{array}{c}\mathrm{BNF}+\mathrm{PQ} \\
(\mathrm{N}=10)\end{array}$ & $\begin{array}{l}\mathrm{HSP}+\mathrm{PQ} \\
(\mathrm{N}=10)\end{array}$ & \multirow[t]{2}{*}{$\begin{array}{c}\mathrm{X}^{2} \\
\text { Test }\end{array}$} & \multirow[t]{2}{*}{$P$ value } \\
\hline & No (\%) & No (\%) & No $(\%)$ & No $(\%)$ & & \\
\hline Congested blood Vessels & $0(0.0)$ & $5(50.0)$ & $2(20.0)$ & $3(30.0)$ & 41.35 & $<0.001^{* *}$ \\
\hline $\begin{array}{l}\text { Irregular shrunken cells and } \\
\text { vacuolated cytoplasm }\end{array}$ & $1(10.0)$ & $6(60.0)$ & $3(30.0)$ & $2(20.0)$ & 54.11 & $<0.001^{* *}$ \\
\hline Degenerative changes & $0(0.0)$ & $5(50.0)$ & $1(0.0)$ & $3(30.0)$ & 48.32 & $<0.001^{* *}$ \\
\hline Apoptotic nuclei & $2(20.0)$ & $7(70.0)$ & $5(50.0)$ & $4(40.0)$ & 64.74 & $<0.001^{* *}$ \\
\hline
\end{tabular}

**: highly significant $(\mathrm{P}:<0.001)$. 
Immunohistochemical staining of spinal cord neurons showed negative immunereactivity in $90 \%$ of rats of control group (Table 14), while, $80 \%$ of rats of paraquat treated group showed strong immunoreactivity (Table 14). Moreover, paraquat + benfotaimine treated group showed negative to moderate to strong positive immunoreactivity in $20 \%, 70 \%$ and $10 \%$ of rats of this group respectively (Table 14). In addition, paraquat + hesperidin treated group showed negative to moderate to strong positive immunoreactivity in $10 \%, 80 \%$ and $10 \%$ of rats of this group respectively (Table 14).

\section{Discussion}

Exposure to environmental hazards including herbicides is one of the challenges that faces the scientists to discover and measure the safety of human health especially in occupational exposure that affect the people medical social and economic sides. Oxidative stress and radicals has been recorded to be the major mechanism causing paraquat (PQ) toxicity [41].

In our study, there were highly significant increase, decreased in MAD and GSH respectively with decrease antioxidant enzyme activities in paraquate treated group indicating oxidative damage. These results are in parallel with Abd El-Rahman et al. [42] who recorded that exposure to PQ significantly increased malondialdehyde (MDA) while decreased glutathione content (GSH) with the enzyme activities in the blood, lung and dorsal aorta indicating oxidative stress and increased lipid peroxidation. Redox cycle is the key of PQ induced toxicity as it is enzymatically reduced, by NADPH-cytochrome P450 reductase [43] and NADHubiquinone oxidoreductase (complex I) [44], to produce a PQ free radical with the subsequent production of the superoxide radical $\left(\mathrm{O}_{2} \bullet^{-}\right)$[45]. hydrogen peroxide $\left(\mathrm{H}_{2} \mathrm{O}_{2}\right)$ and hydroxyl radical $(\mathrm{HO})$. It is skillfully registered that antioxidants entertain a chief role in palliating the devastating effects of oxidative stress on different tissues.

In our study, there was highly significant increase in serum PNF-H level in paraquat treated group that is indicating spinal cord damage. This result is in accordance with Adel et al. [46] who reported that serum pNF-H was highly significant increase in their Multiple sclerosis patients than controls. Neurofilaments,

Table 14. Chi-square test statistical analysis of nitrotyrosine expression in spinal cords of different studied groups.

\begin{tabular}{ccccccc}
\hline \multirow{2}{*}{ Group } & $\begin{array}{c}\text { Control } \\
(\mathrm{N}=10)\end{array}$ & $\begin{array}{c}\mathrm{PQ} \\
(\mathrm{N}=10)\end{array}$ & $\begin{array}{c}\mathrm{BNF}+\mathrm{PQ} \\
(\mathrm{N}=10)\end{array}$ & $\begin{array}{c}\mathrm{HSP}+\mathrm{PQ} \\
(\mathrm{N}=10)\end{array}$ & $\begin{array}{c}\mathrm{X}^{2} \\
\text { Test }\end{array}$ & P value \\
\cline { 2 - 5 } & No (\%) & No (\%) & No (\%) & No (\%) & & \\
\hline Negative (0)/Weak (1) & $9(90.0)$ & $0(0.0)$ & $2(20.0)$ & $1(10.0)$ & & \\
Moderate(2) & $1(10.0)$ & $2(20.0)$ & $7(70.0)$ & $8(80.0)$ & 31.17 & $<0.001^{* *}$ \\
Strong(3) & $0(0.0)$ & $8(80.0)$ & $1(10.0)$ & $1(10.0)$ & & \\
Total & $10(100.0)$ & $10(100.0)$ & $10(100.0)$ & $10(100.0)$ & & \\
\hline
\end{tabular}

**: highly significant $(\mathrm{P}:<0.001)$. 
a major ingredient of neuronal cells, can be freely set into the cerebrospinal fluid and serum in cases of neuronal axonal injury in divergent neurological diseases such as multiple sclerosis.

In our study, there was highly significant increase in serum NSE level in paraquate treated group that is indicating spinal cord damage. This result is in parallel with Shash et al. [47] who reported that NSE major component in the cytoplasm of neuronal cells, its release in the serum at significant high levels specifies neuronal scarring according to Bharosay et al. [48] who announced that endothelial cell death disrupts the blood brain barrier during stroke, and the released cytoplasmic elements from damaged neuronal tissues. Although, Fassbender et al. [49] in his studies, announced that serum NSE levels are less sensitive, and a devastating injury is required to release a detectable authentic differences. This can be explained by the timing of the sample's extraction; also, the use of dissimilar kits.

In our study, there was highly significant increase in serum s100 level in paraquat treated group that is indicating spinal cord damage. This result is in parallel with wei et al. [50] who reported that blood sample from a PQ poisoning patient has estimated significantly increased of S100A8 and S100A9 levels. The expression of S100A8 and S100A9 was also advocated in the lung tissue of PQ-treated rat accompanied with lung destruction. Furthermore, the expression of S100 in patient serum could provide a preferential diagnostic tool and biomarker for predicting PQ poisoning in patients.

The present study showed decrease in differentiated neurons and increase in degenerated neurons. Also, neuropil hemorrhage, vacuolation, dilated congested capillaries and neurogliosis. These findings are in parallel with that declared by Bilian et al. [51] neuronal histopathological findings were moderate neuronal degeneration, edema, gliosis, due to anoxia, and damage to the central white matter and especially the neuronal tissue around the lateral and third ventricles.

Reports subsists that herbicides, including paraquat, may be fated in the mechanism of a neurodegenerative disorder (Parkinson's Disease) specified by degeneration of dopaminergic neurons set into Substantia Nigra and pyramidal tract in spinal cord [52] Additionally, it is recorded that paraquat produces severe behavioural, electro cortical and neurodegenerative side effects when given into several areas of the rat Brain and spinal cord as well as when given systemically [53]. These side effects are prohibited by the administration of $\mathrm{Cu}$-free superoxide dismutase (SOD) in the same sites, an enzyme which converts superoxide anions into hydrogen peroxide, submitting that oxidative stress is incorporated in the neurotoxicity produced by paraquat [54].

Ibi et al. [55] observed that abnormal formation of reactive oxygen species (ROS) may attribute a major role in paraquat-induced neuronal damage. In has been demonstrated that dopaminergic neurons are extremely sensitized to ROS output. Also, exhaustion of glutathione, another factor implied in sustaining both neuronal tissues centrally and peripherally into an antioxidant status, increases liability of dopaminergic neurons to nitric oxide and suppresses the mitochondrial com- 
plex I activity in cells leading to neurotoxic effects [56].

Nitrotyrosine immunostaining was strongly positive in the neuronal cells in PQ treated group. In control, $\mathrm{BNF}+\mathrm{PQ}$, and HSD + PQ groups, proportion of negative to moderate nitrotyrosine immunostaining and low morphologic alterations were observed. This results confirmed by Choong et al. [57] who stated that transgenic mice spinal cord, immunocytochemistry showed strongly immunostained by nitrotyrosine antibodies in neuronal cells, but no nitrotyrosine immunocytochemical reaction in neuronal cells were observed in the spinal cord of the control mice. Other studies have recorded that antioxidants and NOS inhibitor increase SOD life span in neuronal cells in transgenic mouse model. The therapy with antioxidant agents may suppress the neurodegenerative process in human amyotrophic lateral sclerosis, also it has been recorded to reduce of nitrotyrosine production.

Nitrous oxide, free radical, has many useful functions when produced in vivo by neurons and endothelial cells [58]. But, excess NO produces cytotoxicity [59] Nitric oxide significantly interacts with $\mathrm{O}_{2} .^{-}$to give $\mathrm{ONOO}^{-}$[60] Peroxynitrite is pro-oxidant interacting with SOD to form a strong nitrating agent, submitting the nitration of tyrosine of cellular proteins resulting in cellular dysfunction and death [61].

Watanabe et al. [62] reported the induction of nNOS and SOD after spinal cord ischemia, with most motor neurons showing crucial death. This result recommended that induction of both nNOS and SOD with production of $\mathrm{NO}_{2}$-Tyr. It was also found that the nitrotyrosine immunopositivity rises with development of anterior horn cell degeneration and generation of reactive astrocytes. These results suggest that oxidative damage in SOD transgenic mice starting the degeneration of motor neurons and neuronal death.

Chou et al. [63] have recorded that neurofilamentous gathering in the motor neurons of patients with amyotrophic lateral sclerosis, were immunoreactive with an antityrosine antibody. Many of the degenerated neurons represented positive nitrotyrosine immunoreactivity, associated the distributed reactive astrocytes in the neuropil of the anterior horns and in the corticospinal tracts were obviously immunostained for nitrotyrosine.

Cha et al. [64] described the presence of nitrotyrosine-immunoreactive astrocytes and motor neurons in the spinal cords of mutant SOD transgenic mice, when were clinically evident this noticeable result is similar to that in sporadic ALS patients [65] These results indicate that the extent of nitrotyrosine staining harmonized with the degeneration of anterior horn cells and the number of reactive astrocytes and that nitrotyrosine expression may be deleterious to the motor neuron system and be incorporated in the neurotoxic mechanism [66].

In our study, there was highly significant difference in levels of MAD, GPx, and nonsignificant difference in PNF-H, NES, and S100 levels in rats of BNF + PQ and HSD + PQ groups.

Lukienko et al. [67] found that thiamine is not diminished inside the cell by 
PQ exposure, advocating that no considerable amounts of thiamine have reacted with ROS produced in the presence of PQ. On the other hand, it was recommended that the oxidation of thiamine by ROS mainly produces thiochrome. They determined no increase in thiochrome release by our cells after PQ exposure.

In our study, co-administration of BFM and HSD cause improvement in levels of MAD, GPx, PNF-H, NES, and S100 levels in rats, it was nearly similar to control group levels. In these groups, pretreatment with BFM and HSD decrease and increase the MAD and GSH levels respectively with increase antioxidant enzymes activities and decrease PNF-H, NES, and S100 levels beside the improvement of histopathological changes of spinal cords.

Benfotiamine (BNF) is an artificially produced thiamine precursor with elevated bioavailability. It has advantageous effects against neurodegenerative diseases in mouse. BNF protects the cells against PQ induced toxicity with high efficacy. The main metabolites of BNF were thiamine and S-benzoylthiamine (S-BT). Treatment with it produces a giant increase in intracellular import of thiamine. Also BFT, S-BT and thiamine all safeguard the cells against oxidative stress, submitting an antioxidant effect of thiamine. Thiamine has a secondary effect likely mediated by few antioxidants signaling pathways and its thiol form [68].

Although, it can be shown that BNF was approximately as defensive agent in the presence of the above results, but also, it is shown that the additive protective effects of BFT and SuBT against PQ toxicity are related to the important intracellular accumulation of thiamine. Thiamine protects the devastating effects of ROS either by direct or indirect antioxidant effects. Direct antioxidant effects has been recorded by [69] that thiamine and ThDP have free radical scavenging activities in vitro. Sambon et al. [70] showed that thiamine and ThDP presented suppressive effects on superoxide production. The probability of a protection against $P Q$ by a direct interaction between thiamine and superoxide should be appraised.

Hesperidin supplementation during exposure to $P Q$ has remarkable decreased lipid peroxidation and increased GSH in spinal cord. The decrease of oxidative stress in blood was associated with normalization of antioxidant enzymes activities. In the same way decreased oxidative stress in tissues as lung and dorsal aorta was accompanied by improvement of the histopathological changes in both tissues. The modifier role of HDN could be assigned to its capacity to suppress inflammation [71] by interacting with arachidonic acid metabolism, histamine release and by suppressing lipoxygenase, cyclooxygenase and xanthine oxidase [72]. Additionally, HDN has antioxidant [73] and metal chelating capacity by suppressing the superoxide derived Fenton reaction [74] The free radical scavenging ability [75] attributed to its sulfhydryl groups which interact with free radicals exactly peroxynitrite [76] and hydroxyl radical so, it is playing a major role in antioxidant defense system [77].

\section{Conclusion}

This study provides evidence that PQ adversely affects spinal cord tissues by in- 
creasing oxidative damage. The benfotaimine and hesperidin administration is highly effective in preventing neurotoxicity. Further studies are recommended on larger population, longer duration and other markers to assess the toxicity.

\section{Conflicts of Interest}

The authors declare no conflict of interests in relation to this article.

\section{Acknowledgements}

The authors gratefully acknowledge the support and help provided by all the staff of animal House, Zagazig University Hospitals.

\section{References}

[1] Ahmed, M.M. (2010) Radio and Chemo Protective Properties of Hesperidin against Genotoxicity Induced by Gamma Radiation and/or Paraquat in Rat Bone Marrow Cells. Egyptian Journal of Radiation Sciences and Applications, 23, 233-244.

[2] El Kader, M.A.A., Fyiad, A.A. and Soliman, M.S. (2006) Protective Role of Aqueous Garlic Extract on Paraquat Induced Lung Injury in Rats. Egyptian Journal of Biomedical Sciences, 20, 125-136.

[3] He, X., Wang, L., Szklarz, G., Bi, Y. and Ma, Q. (2012) Resveratrol Inhibits ParaquatInduced Oxidative Stress and Fibrogenic Response by Activating the Nuclear Factor Erythroid 2-Related Factor 2 Pathway. Journal of Pharmacology and Experimental Therapeutics, 342, 81-90. https://doi.org/10.1124/jpet.112.194142

[4] Tanner, C.M., Kamel, F., Ross, G.W., Hoppin, J.A., Goldman, S.M., Korell, M., et al. (2011) Rotenone, Paraquat, and Parkinson's Disease. Environmental Health Perspectives, 119, 866-872. https://doi.org/10.1289/ehp.1002839

[5] Sen, S., Chakraborty, R., Sridhar, C., Reddy, Y. and De, B. (2010) Free Radicals, Antioxidants, Diseases and Phytomedicines: Current Status and Future Prospect. International Journal of Pharmaceutical Sciences Review and Research, 3, 91-100.

[6] Bettendorff, L. (2013) Thiamine. In: Zempleni, J., Suttie, J., Gregory III, J.F. and Stover, P., Eds., Handbook of Vitamins, 5th Edition, CRC Press, Boca Raton, 268-323. https://doi.org/10.1201/b15413-8

[7] Mkrtchyan, G., Aleshin, V., Parkhomenko, Y., Kaehne, T. and Luigi Di Salvo, M. (2015) Molecular Mechanisms of the Non-Coenzyme Action of Thiamin in Brain: Biochemical, Structural and Pathway Analysis. Scientific Reports, 5, Article No. 12583. https://doi.org/10.1038/srep12583

[8] Hammes, H.P., Du, X., Edelstein, D., Taguchi, T., Matsumura, T., Ju, Q., et al. (2013) Benfotiamine Blocks Three Major Pathways of Hyperglycemic Damage and Prevents Experimental Diabetic Retinopathy. Nature Medicine, 9, 294-299. https://doi.org/10.1038/nm834

[9] Pan, X., Gong, N., Zhao, J., Yu, Z., Gu, F., Chen, J., et al. (2010) Powerful Beneficial Effects of Benfotiamine on Cognitive Impairment and Beta-Amyloid Deposition in Amyloid Precursor Protein/Presenilin-1 Transgenic Mice. Brain, 133, 1342-1351. https://doi.org/10.1093/brain/awq069

[10] Tapias, V., Jainuddin, S., Ahuja, M., Stack, C., Elipenahli, C., Vignisse, J., et al. (2018) Benfotiamine Treatment Activates the Nrf2/ARE Pathway and Is Neuroprotective in a Transgenic Mouse Model of Tauopathy. Human Molecular Genetics, 27, 28742892. https://doi.org/10.1093/hmg/ddy201 
[11] Markova, N., Bazhenova, N., Anthony, D., Vignisse, J., Svistunov, A., Lesch, K., Bettendorff, L. and Strekalova, T. (2017) Thiamine and Benfotiamine Improve Cognition and Ameliorate GSK-3 $\beta$-Associated Stress-Induced Behaviours in Mice. Progress in Neuro-Psychopharmacology and Biological Psychiatry, 75, 148-156. https://doi.org/10.1016/j.pnpbp.2016.11.001

[12] Raghunath, A., Sundarraj, K., Nagarajan, R., Arfuso, F., Bian, J., Kumar, A., Sethi, G. and Perumal, E. (2018) Antioxidant Response Elements: Discovery, Classes, Regulation and Potential Applications. Redox Biology, 17, 297-314.

https://doi.org/10.1016/j.redox.2018.05.002

[13] Pavlov, D., Markova, N., Bettendorff, L., Chekhonin, V., Pomytkin, I., Lioudyno V., et al. (2017) Elucidating the Functions of Brain GSK3a: Possible Synergy with GSK3 $\beta$ Upregulation and Reversal by Antidepressant Treatment in a Mouse Model of Depressive-Like Behaviour. Behavioural Brain Research, 335, 122-127. https://doi.org/10.1016/j.bbr.2017.08.018

[14] Manach, C., Morand, C., Gil-Izquierdo, A., Bouteloup-Demange, C. and Remesy, C. (2003) Bioavailability in Humans of the Flavanones Hesperidin and Narirutin after the Ingestion of Two Doses of Orange Juice. European Journal of Clinical Nutrition, 57, 235-242. https://doi.org/10.1038/sj.ejcn.1601547

[15] Akiyama, S., Katsumata, S., Suzuki, K.M., Ishimi, Y., Wu, J. and Uehara, M. (2010) Dietary Hesperidin Exertshypoglycemic and Hypolipidemic Effects in StreptozotocinInduced Marginal Type 1 Diabetic Rats. Journal of Clinical Biochemistry and Nutrition, 46, 87-92. https://doi.org/10.3164/jcbn.09-82

[16] Li, C. and Schluesener, H. (2015) Health-Promoting Effects of the Citrus Flavanone Hesperidin. Critical Reviews in Food Science and Nutrition, 57, 613-631. https://doi.org/10.1080/10408398.2014.906382

[17] Kuntić, V., Brborić, J., Holclajtner-Antunović, I. and Uskoković-Marković, S. (2014) Evaluating the Bioactive Effects of Flavonoid Hesperidin-A New Literature Data Survey. Vojnosanitetski Pregled, 71, 60-65. https://doi.org/10.2298/VSP1401060K

[18] Alshatwi, A.A., Ramesh, E., Periasamy, V.S. and Subash-Babu, P. (2013) The Apoptotic Effect of Hesperetin on Human Cervical Cancer Cells Is Mediated through Cell Cycle Arrest, Death Receptor, and Mitochondrial Pathway. Fundamental \& Clinical Pharmacology, 27, 581-592. https://doi.org/10.1111/j.1472-8206.2012.01061.x

[19] Institute of Laboratory Animal Resources (1996) Guide for the Care and Use of Laboratory Animals. 7th Edition, National Academy Press, Washington DC, 125.

[20] Cuschieri, A. and Backer, P. (1977) Introduction to Research in Medical Sciences. Churchill Livingstone, Edinburgh, 112-120.

[21] Semler, D. (1992) The Rat Toxicology. In: Gad, S.C. and Chenglis, C.P., Eds., Animal Model in Toxicology, Marcel Dekker, Inc., New York, Basel and Hong Kong, ch.2, 21-75.

[22] Abo-Shafy, A., Sakr, S., El-Saadany, M. and Abd El-Samei, H. (1997) Histological and Histochemical Effects of the Herbicide Paraquat on the Liver of Albino Rats. Egyptian Journal of Radiation Sciences and Application, 10, 901-920.

[23] Ceylan-Isik, A.F., Wu, S., Li, Q., Li, S.Y. and Ren, J. (2019) High-Dose Benfotiamine Rescues Cardiomyocyte Contractile Dysfunction in Streptozotocin-Induced Diabetes Mellitus. Journal of Applied Physiology, 100, 150-156.

https://doi.org/10.1152/japplphysiol.00988.2005

[24] Hosseinimehr, S.J. and Nemati, A. (2006) Radio Protective Effects of Hesperidin against Gamma Irradiation in Mouse Bone Marrow Cell. The British Journal of Ra- 
diology, 79, 415-418. https://doi.org/10.1259/bjr/40692384

[25] Benitz, K.F. (1979) Methods of Toxicology. Payed-Blackwell, G.E., Ed., Scientific publication, Oxford, Edinburgh, 82.

[26] Bala, U., Tan, K., Ling, K. and Cheah, P.-S. (2014) Harvesting the Maximum Length of Sciatic Nerve from Adult Mice: A Step-by-Step Approach. BMC Research Notes, 7, Article No. 714. https://doi.org/10.1186/1756-0500-7-714

[27] Bancroft, J. and Gamble, M. (2008) Theory and Practice of Histological Techniques. 6th Edition, Churchill Livingston, New York, Edinburgh, London, 165-175.

[28] Wen, J., Sun, D. and Tan, J. (2015) A Consistent, Quantifiable, and Graded Rat Lumbosacral Spinal Cord Injury Model. Journal of Neurotrauma, 32, 875-892.

https://doi.org/10.1089/neu.2013.3321

[29] Rigaud, M., Gemes, G., Barabas, M., Chernoff, D., Abram, S., Stucky, C. and Hogan, Q. (2008) Species and Strain Differences in Rodent Sciatic Nerve Anatomy: Implications for Studies of Neuropathic Pain. Pain, 136, 188-201.

https://doi.org/10.1016/j.pain.2008.01.016

[30] Ellman, G.L. (1959) Tissue Sulfhydryl Groups. Archives of Biochemistry and Biophysics, 82, 70-77. https://doi.org/10.1016/0003-9861(59)90090-6

[31] Draper, H.H. and Hadley, M. (1990) Malondialdehyde Determination as Index of Lipid Peroxidation. Methods in Enzymology, 86, 421-431. https://doi.org/10.1016/0076-6879(90)86135-I

[32] Aebi, H. (1984) Catalase In Vitro. Methods in Enzymology, 105, 121-126. https://doi.org/10.1016/S0076-6879(84)05016-3

[33] Beauchamp, C. and Fridovich, I. (1971) Superoxide Dismutase: Improved Assays and an Assay Applicable to Acrylamide Gels. Analytical Biochemistry, 144, 276-287. https://doi.org/10.1016/0003-2697(71)90370-8

[34] Flohe, A. and Günzler, W.A. (1984) Assays of Glutathione Peroxidase. Methods in Enzymology, 105, 114-121. https://doi.org/10.1016/S0076-6879(84)05015-1

[35] Kuhle, J., Kropshofer, H., Dieter, A., Kundu, U. and Meinert, R. (2019) Blood Neurofilament Light Chain as a Biomarker of MS Disease Activity and Treatment Response. Neurology, 92, e1007-e1015. https://doi.org/10.1212/WNL.0000000000007032

[36] Shash, H., Abdelrazek, R., Abdelgeleel, N., Ahmed, R. and El-baih, A. (2021) Validity of Neuron-Specific Enolase as a Prognostic Tool in Acute Ischemic Stroke in Adults at Suez Canal University Hospital. The Egyptian Journal of Neurology, Psychiatry and Neurosurgery, 57, Article No. 30. https://doi.org/10.1186/s41983-021-00268-6

[37] Latife, B., Ayhan, A., Feyzullah, B. and Anıl, İ. (2009) Immunohistochemical Studies on S100 Reactivity in Chicks Experimentally Infected with Eimeria tenella I: The Localization of S100 Protein and Its Subunits $\alpha$ and $\beta$ in Stages of Eimeria tenella. Turkish Journal of Veterinary and Animal Sciences, 33, 121-129.

[38] Horobin, R.W. and Bancroft, J.D. (1998) Hematoxylin and Eosin as an Oversight Stain. In: Troubleshooting Histology Stains, First Edition, Chapter 22, Churchil Livingston, Pearson Professional limited Press, New York, London, and Madrid Melbourne, Sanfrancisco and Tokyo, 88-93.

[39] Kammerer, R., Stober, D., Singer, B., Obrink, B. and Reimann, J. (2001) Carcinoembryonic Antigen-Related Cell Adhesion Molecule 1 on Murine Dendritic Cells Is a Potent Regulator of T Cell Stimulation. The Journal of Immunology, 166, 6537-6544. https://doi.org/10.4049/jimmunol.166.11.6537

[40] Zimmermann, A. (2014) Value of Immunohistochemistry in the Detection of BRAFV600E Mutations in Fine-Needle Aspiration Biopsies of Papillary Thyroid Carcinoma. Can- 
cer Cytopathology, 122, 48-58. https://doi.org/10.1002/cncy.21352

[41] Meng, X.X., Wang, R.L., Gao, S., Xie, H., Tan, J.T. and Qian, Y.B. (2013) Effect of Ulinastatin on Paraquat-Inducedoxidative Stress in Human Type II Alveolar Epithelial Cells. World Journal of Emergency Medicine, 4, 133-137.

https://doi.org/10.5847/wjem.j.issn.1920-8642.2013.02.009

[42] Abd El-Rahman, N.A., Kamal El-Dein, E.M., Abd El-Hady, A.M. and Soliman, S.M. (2016) Effect of Hesperidin on $\gamma$-Radiation- and/or Paraquat Herbicide-Induced Biochemical, Hematological and Histopathological Changes in Rats. Pakistan Journal of Zoology, 48, 1407-1415.

[43] Clejan, L. and Cederbaum, A.I. (1989) Synergistic Interaction between NADPHcytochrome P-450 Reductase, Paraquat and Iron in the Generation of Active Oxygen Radicals. Biochemical Pharmacology, 38, 1779-1786.

https://doi.org/10.1016/0006-2952(89)90412-7

[44] Fukushima, T., Yamada, K., Isobe, A., Shiwaku, K. and Yamane, Y. (1993) Mechanism of Cytotoxicity of Paraquat. I. NADH Oxidation and Paraquat Radical Formation via Complex I. Experimental and Toxicologic Pathology, 45, 345-349. https://doi.org/10.1016/S0940-2993(11)80424-0

[45] Dicker, E. and Cederbaum, A.I. (1991) NADH-Dependent Generation of Reactive Oxygen Species by Microsomes in the Presence of Iron and Redox Cycling Agents. Biochemical Pharmacology, 42, 529-535. https://doi.org/10.1016/0006-2952(91)90315-V

[46] Adel, A., El Ebeary, M., Aidaros, M. and Shawky, N. (2020) Serum Phosphorylated Neurofilament Heavy Chain as a Marker of Axonal Injury and Disease Severity in Multiple Sclerosis Patients. Medicine Updates, 2, 38-54.

https://doi.org/10.21608/muj.2020.29230.1010

[47] Bharosay, A., Bharosay, V.V., Varma, M., Saxena, K., Sodani, A. and Saxena, R. (2012) Correlation of Brain Biomarker Neuron Specific Enolase (NSE) with Degree of Disability and Neurological Worsening in Cerebrovascular Stroke. Indian Journal of Clinical Biochemistry, 27, 186-190. https://doi.org/10.1007/s12291-011-0172-9

[48] Fassbender, K., Schmidt, R., Schreiner, A., Fatar, M., Mühlhauser, F., Daffertshofer, M., et al. (2007) Leakage of Brain-Originated Proteins in Peripheral Blood: Temporal Profile and Diagnostic Value in Early Ischemic Stroke. Journal of the Neurological Sciences, 148, 101-105. https://doi.org/10.1016/S0022-510X(96)05351-8

[49] Wei, L., Wang, Y., Lin, L., Zhang, L., Shi, Y., Xiang, P., Cao, S., Shen, M. and Yang, P. (2018) Identification of Potential Serum Biomarkers of Acute Paraquat Poisoning in Humans Using an iTRAQ Quantitative Proteomic. RSC Advances, 19, 10598-10609. https://doi.org/10.1039/C7RA12956D

[50] Bailin, W., Song, B., Yang, H., Huang, B., Chi, B., Guo, Y. and Liu, H. (2013) Central Nervous System Damage Due to Acute Paraquat Poisoning: An Experimental Study with Rat Model. Neurotoxicology, 35, 62-70. https://doi.org/10.1016/j.neuro.2012.12.001

[51] Thiruchelvam, M., Richfield, E.K., Baggs, R.B., Tank, A.W. and Cory-Slechta, D.A. (2000) The Nigrostriatal Dopaminergic System as a Preferential Target of Repeated Exposures to Combined Paraquat and Maneb: Implications for Parkinson's Disease. Journal of Neuroscience, 20, 9207-9214. https://doi.org/10.1523/JNEUROSCI.20-24-09207.2000

[52] Brooks, A.I., Chadwick, C.A., Gelbard, H.A., Cory-Slechta, D.A. and Federoff, H.J. (1999) Paraquat Elicited Neurobehavioural Syndrome Caused by Dopaminergic Neuron Loss. Brain Res, 823, 1-10. https://doi.org/10.1016/S0006-8993(98)01192-5

[53] Lannone, M., Ciriolo, M.R., Rotilio, G. and Nistico, G. (1991) Intra-Nigral Infusion 
of Cu-Free Superoxide Dismutase Prevents Paraquat-Induced Behavioural Stimulation and ECoG Epileptogenic Discharges in Rats. Neuropharmacology, 30, 893-898. https://doi.org/10.1016/0028-3908(91)90124-T

[54] Ibi, M., Sawada, H., Kume, T., Katsuki, H., Kaneko, S., Shimohama, S. and Akaike, A. (1999) Depletion of Intracellular Glutathione Increases Susceptibility to Nitric Oxide in Mesencephalic Dopaminergic Neurons. Journal of Neurochemistry, 73, 1696-1703. https://doi.org/10.1046/j.1471-4159.1999.731696.x

[55] Jha, N., Jurma, O., Lalli, G., Liu, Y., Pettus, E.H., Greenamyre, J.T., Liu, R.M., Forman, H.J. and Andersen, J.K. (2000) Glutathione Depletion in PC12 Results in Selective Inhibition of Mitochondrial Complex I Activity: Implications for Parkinson's Disease. Journal of Biological Chemistry, 275, 26096-26101. https://doi.org/10.1074/jbc.M000120200

[56] Cha, C.I., Chung, Y.H., Shin, C.M., Shin, D.H., Kim, Y.S., Gurney, M.E., et al. (2000) Immunocytochemical Study on the Distribution of Nitrotyrosine in the Brain of the Transgenic Mice Expressing a Human Cu/Zn SOD Mutation. Brain Research, 853, 156-161. https://doi.org/10.1016/S0006-8993(99)02302-1

[57] Moncada, S. (1992) The L-Arginine: Nitric Oxide Pathway. Acta Physiologica Scandinavica, 145, 201-227. https://doi.org/10.1111/j.1748-1716.1992.tb09359.x

[58] Stefanovic-Racic, M., Stadler, J. and Evans, C.H. (1993) Nitric Oxide Synthesis and Its Regulation by Rabbit Synoviocytes. Arthritis \& Rheumatism, 36, 1036-1044. https://doi.org/10.1002/art.1780360803

[59] Huie, R.E. and Padmaja, S. (1993) The Reaction of NO with Superoxide. Free Radical Research Communications, 18, 195-199. https://doi.org/10.3109/10715769309145868

[60] Beckman, J.S., Carson, M., Smith, C.D. and Koppenol, W.H. (1993) ALS, SOD and Peroxinitrite. Nature, 364, 584. https://doi.org/10.1038/364584a0

[61] Watanabe, M., Sakurai, M., Abe, K., Aoki, M., Sadahiro, M., Tabayashi, K., Okamoto, K., Shoji, M. and Iotyama, Y. (1996) Inductions of Cu/Zn Superoxide Dismutase- and Nitric Oxide Synthase-Like Immunoreactivities in Rabbit Spinal Cord after Transient Ischemia. Brain Research, 732, 69-74. https://doi.org/10.1016/0006-8993(96)00490-8

[62] Chou, S., Wang, H. and Taniguchi, A. (2006) Role of SOD-1 and Nitric Oxide/Cyclic GMP Cascade on Neurofilament Aggregation in ALS/ MND. Journal of the Neurological Sciences, 139, 16-26. https://doi.org/10.1016/0022-510X(96)00090-1

[63] Cha, C.I., Chung, Y.H., Shin, C., Shin, D.H., Kim, Y.S., Gurney, M.E., et al. (2000) Immunocytochemical Study on the Distribution of Nitrotyrosine in the Brain of the Transgenic Mice Expressing a Human Cu/Zn SOD Mutation. Brain Research, 853, 156-161. https://doi.org/10.1016/s0006-8993(99)02302-1

[64] Sasaki, S., Shibata, N., Komori, T. and Iwata, M. (2000) iNOS and Nitrotyrosine Immunoreactivity in Amyotrophic Lateral Sclerosis. Neuroscience Letters, 291, 44-48. https://doi.org/10.1016/S0304-3940(00)01370-7

[65] Shoichi, S., Hitoshi, W., Koji, A. and Makoto, I. (2001) Inducible Nitric Oxide Synthase (iNOS) and Nitrotyrosine Immunoreactivity in the Spinal Cords of Transgenic Mice with a G93A Mutant SOD1 Gene. Journal of Neuropathology \& Experimental Neurology, 60, 839-846. https://doi.org/10.1093/jnen/60.9.839

[66] Lukienko, P.I., Mel'nichenko, N.G., Zverinskii, I.V. and Zabrodskaya, S.V. (2000) Antioxidant Properties of Thiamine. Bulletin of Experimental Biology and Medicine, 130, 874-876. https://doi.org/10.1007/BF02682257

[67] Margaux, S., Aurore, N., Alice, D., Julie, V., Pierre, W., Marianne, F. and Lucien, B. (2019) Thiamine and Benfotiamine Protect Neuroblastoma Cells against Paraquat 
and $\beta$-Amyloid Toxicity by a Coenzyme-Independent Mechanism. Heliyon, 5, Article No. e01710. https://doi.org/10.1016/j.heliyon.2019.e01710

[68] Pan, X., Chen, Z., Fei, G., Pan, S., Bao, W., Ren, S., Guan, Y. and Zhong, C. (2016) Long-Term Cognitive Improvement after Benfotiamine Administration in Patients with Alzheimer's Disease. Neuroscience Bulletin, 32, 591-596.

https://doi.org/10.1007/s12264-016-0067-0

[69] Sambon, M., Gorlova, A., Demelenne, A., Alhama-Riba, J., Coumans, B., Lakaye, B., Wins, P., Fillet, M., Anthony, D.C. and Strekalova, T. (2020) Dibenzoylthiamine Has Powerful Antioxidant and Anti-Inflammatory Properties in Cultured Cells and in Mouse Models of Stress and Neurodegeneration. Biomedicines, 8, Article No. 361. https://doi.org/10.3390/biomedicines8090361

[70] Parhiz, H., Roohbakhsh, A., Soltani, F., Rezaee, R. and Iranshahi, M. (2015) Antioxidant and Anti-Inflammatory Properties of the Citrus Flavonoids Hesperidin and Hesperetin: An Updated Review of Their Molecular Mechanisms and Experimental Models. Phytotherapy Research, 29, 323-331. https://doi.org/10.1002/ptr.5256

[71] Berkarda, B., Koyuncu, H., Soybir, G.T. and Baykut, F. (1998) Inhibitory Effect of Hesperidin on Tumor Initiation and Promotion in Mouse Skin. Research in Experimental Medicine, 198, 93-99. https://doi.org/10.1007/s004330050093

[72] Kalpana, K.B., Devipriya, N., Srinivasan, M., Vishwanathan, P., Thayalan, K. and Menon, V.P. (2011) Evaluating the Radioprotective Effect of Hesperidin in the Liver of Swiss Albino Mice. European Journal of Pharmacology, 658, 206-212. https://doi.org/10.1016/j.ejphar.2011.02.031

[73] Malesev, D. and Kunti, V. (2007) Investigation of Metalflavonoid Chelates and the Determination of Flavonoids via Metal-Flavonoid Complexing Reactions. Journal of the Serbian Chemical Society, 72, 921-939.

[74] Jain, D.P., Pancholi, S.S. and Patel, R. (2011) Synergistic Antioxidant Activity of Green Tea with Some Herbs. Journal of Advanced Pharmaceutical Technology \& Research, 2, 177-183. https://doi.org/10.4103/2231-4040.85538

[75] Gaur, V., Aggorwal, A. and Kumar, A. (2011) Possible Nitric Oxide Mechanism in the Protective Effect of Hesperidin against Ischemic Perfusion Cerebral Injury in Rats. Indian Journal of Experimental Biology, 49, 609-618.

[76] Pradeep, K., Ko, K.C., Choi, M.H., Kang, J.A., Chung, Y.J. and Park, S.H. (2012) Protective Effect of Hesperidin, a Citrus Flavanoglycone, against $\gamma$-Radiation-Induced Tissue Damage in Sprague-Dawley Rats. Journal of Medicinal Food, 15, 419-427. https://doi.org/10.1089/jmf.2011.1737

[77] Gandhi, C., Upaganalawar, A. and Balaraman, R. (2009) Protection against in Vivo Focal Myocardial Ischemia/Reperfusion Injury-Induced Arrhythmias and Apoptosis by Hesperidin. Free Radical Research, 43, 817-827.

https://doi.org/10.1080/10715760903071656 